\title{
Plasticity of First-Order Sensory Synapses: Interactions between Homosynaptic Long-Term Potentiation and Heterosynaptically Evoked Dopaminergic Potentiation
}

\author{
Sanjay S. Kumar ${ }^{2}$ and Donald S. Faber ${ }^{1}$ \\ ${ }^{1}$ Department of Neurobiology and Anatomy, Medical College of Pennsylvania-Hahnemann University, Philadelphia, \\ Pennsylvania 19129, and 2Neuroscience Graduate Group, The David Mahoney Institute of Neurological Sciences, \\ University of Pennsylvania School of Medicine, Philadelphia, Pennsylvania 19104
}

Persistent potentiations of the chemical and electrotonic components of the eighth nerve (NVIII) EPSP recorded in vivo in the goldfish reticulospinal neuron, the Mauthner cell, can be evoked by afferent tetanization or local dendritic application of an endogenous transmitter, dopamine (3-hydroxytyramine). These modifications are attributable to the activation of distinct intracellular kinase cascades. Although dopamine-evoked potentiation (DEP) is mediated by the cAMP-dependent protein kinase (PKA), tetanization most likely activates a $\mathrm{Ca}^{2+}$ dependent protein kinase via an increased intracellular $\mathrm{Ca}^{2+}$ concentration. We present evidence that the eighth nerve tetanus that induces LTP does not act by triggering dopamine release, because it is evoked in the presence of a broad spectrum of dopamine antagonists. To test for interactions between these pathways, we applied the potentiating paradigms sequentially. When dopamine was applied first, tetanization produced additional potentiation of the mixed synaptic response, but when the sequence was reversed, DEP was occluded, indicating that the synapses potentiated by the two procedures belong to the same or overlapping populations. Experiments were conducted to determine interactions between the underlying regulatory mechanisms and the level of their convergence. Inhibiting PKA does not impede tetanus-induced LTP, and chelating postsynaptic $\mathrm{Ca}^{2+}$ with BAPTA does not block DEP, indicating that the initial steps of the induction processes are independent. Pharmacological and voltage-clamp analyses indicate that the two pathways converge on functional AMPA/kainate receptors for the chemically mediated EPSP and gap junctions for the electrotonic component or at intermediaries common to both pathways. A cellular model incorporating these interactions is proposed on the basis of differential modulation of synaptic responses via receptor-protein phosphorylation.

Key words: synaptic plasticity; long-term potentiation; dopamine-evoked potentiation; intracellular mechanisms; Mauthner cell; phosphorylation; glutamate receptors
Despite recent advances (Gribkoff and Ashe, 1984; Sarvey et al., 1989; Frey et al., 1993; Villani and Johnston, 1993; Huang and Kandel, 1994, 1995; Staubli and Otaky, 1994; Otmakhova and Lisman, 1996), the precise nature and functional significance of bioaminergic modulation of activity-dependent plasticity have remained mainly unexplored at the cellular level. Here we examine interactions between a catecholamine (dopamine) and a longterm potentiation (LTP), namely, a sustained increase in the efficacy of synaptic transmission induced by means of brief repetitive activation of presynaptic excitatory afferent fibers (Bliss and Lomo, 1973).

A pair of goldfish reticulospinal neurons, the Mauthner cells (M-cells) and their afferents, represent a miniature nervous system (Kuffler et al., 1984) that combines many of the synaptic mechanisms known at present (Korn et al., 1990). Owing to their size, accessibility in vivo, and the fact that they are present as only a single pair, the M-cells and their associated neural circuits have

\footnotetext{
Received June 8, 1998; revised Dec. 14, 1998; accepted Dec. 16, 1998.

This work was supported by National Institutes of Health Grant NS 15335 to D.S.F. We are grateful to Drs. K. Engisch, M. Pinter, Brian Salzberg, Marc Dichter, and Mike Nusbaum for critically reading earlier versions of this manuscript and for their helpful comments. We also thank Maurice Volaski for his assistance with data acquisition and Kathy Golden for typing this manuscript.

Correspondence should be addressed to Dr. Donald S. Faber, Department of Neurobiology and Anatomy, Medical College of Pennsylvania-Hahnemann University, Philadelphia, PA 19129.

Copyright (C) 1999 Society for Neuroscience $\quad 0270-6474 / 99 / 191620-16 \$ 05.00 / 0$
}

been well characterized both morphologically and electrophysiologically (Furshpan and Furukawa, 1962; Furshpan, 1964; Faber and Korn, 1978; Faber et al., 1991). In this system the synaptic efficacy of mixed (electrotonic and chemical) excitatory contacts between first-order auditory (NVIII) afferents and the M-cell is potentiated by patterned electrical excitation of the sensory afferents (Yang et al., 1990) and the local application of dopamine (Pereda et al., 1992). The M-cells thus represent a model system in which both homo- and heterosynaptic potentiations of a common set of inputs are manifest in a single neuron. Whether the enhancements induced by the two potentiating paradigms and their respective intracellular pathways interact with each other or act independently remains unknown.

Previous work has demonstrated that induction of homosynaptic LTP in this system involves the activation of NMDA receptors and a subsequent postsynaptic increase in the intracellular calcium concentration (Yang et al., 1990). Thus, the persistent potentiation of the M-cell synapses has a number of features in common with the analogous processes in hippocampus (Bliss and Collingridge, 1993). In contrast, the dopamine-evoked potentiation (DEP) is mediated by the activation of dopamine D1/D5 receptors, leading to activation of the cAMP-dependent protein kinase, PKA (Wolszon and Faber, 1989; Pereda et al., 1992, 1994). Furthermore, the synaptic bed between the club endings and the distal lateral dendrite receives a dopaminergic innervation (Pereda et al., 1992). Given the close proximity of dopami- 
nergic varicosities to the dendrite and the NVIII endings, we asked if the LTP could be mediated by tetanus-induced release of dopamine, for example by the activation of polysynaptic connections. Although dopamine-evoked potentiations were blocked in the presence of both specific and broad-spectrum dopamine receptor antagonists, afferent tetanization still produced robust potentiation of the synaptic responses, indicating that tetanusinduced LTP occurs independently of dopamine release. Interactions between the two potentiating pathways were tested by applying the paradigms sequentially. Our results suggest that the synapses subjected to DEP are also the ones potentiated during tetanus-induced LTP, and the two paradigms share a common intermediate step or target. We then asked whether a cAMP PKA-dependent step or the elevation of intracellular $\mathrm{Ca}^{2+}$ might be the point of convergence for these two modulations. The data support the alternative conclusion that the initial induction steps are independent and the convergence occurs downstream, possibly at the level of the target proteins themselves.

\section{MATERIALS AND METHODS}

General procedures. Adult goldfish (Carassius auratus) were anesthetized by immersion in ice water and subsequently immobilized by an intramuscular injection of D-tubocurarine $(1 \mu \mathrm{g} / \mathrm{gm}$ body weight $)$ after being placed in the recording chamber. Cooled aerated tap water was perfused through the mouth $(30-50 \mathrm{ml} / \mathrm{min})$ and over the gills. Standard surgical procedures described previously (Faber and Korn, 1978; Wolszon and Faber, 1989) were used in all experiments to expose the medulla and the posterior branch of the ipsilateral auditory nerve (NVIII). Bipolar stimulating electrodes (31-05-3PB, Haer, Brunswick, ME) on the nerve and the spinal column were used for ortho- and antidromic activation of the M-cell, respectively. A perfusion pipette placed near the medullary surface was used for continuous superfusion $(3 \mathrm{ml} / \mathrm{min})$ of the brain with a modified Cortland's saline [containing (in mM): $124 \mathrm{NaCl}, 5.1 \mathrm{KCl}, 3.0$ $\mathrm{NaH}_{2} \mathrm{PO}_{4} \cdot \mathrm{H}_{2} 0,0.9 \mathrm{MgSO}_{4}, 5.6$ dextrose, $1.6 \mathrm{CaCl}_{2} \cdot 2 \mathrm{H}_{2} 0$, and 20 HEPES, $\mathrm{pH}$ 7.2]. Voltage recordings from the M-cell lateral dendrite ( $\sim 1.5 \mathrm{~mm}$ below the brain surface) were made with glass micropipettes filled with $2.5 \mathrm{M}$ potassium chloride (6-10 $\mathrm{M} \Omega$ electrode resistance). After the soma of the M-cell was first localized on the basis of the characteristic large extracellular antidromic field potential recorded in the region of the axon cap of the M-cell, the electrode was moved $\sim 250-300 \mu \mathrm{m}$ laterally for intradendritic recordings in the vicinity of the synaptic input (see Fig. $1 A$ ). The eighth nerve stimulus intensity (0.1-0.5 $\mathrm{mA}$ ) was adjusted such that the range of response amplitudes, measured from baseline, was $8-12 \mathrm{mV}$ for the electrotonic coupling potential (e) and $2-8 \mathrm{mV}$ for the chemical EPSP $(c)$. Stronger stimuli were not used, because they tended to evoke orthodromic action potentials either in the control or after potentiations occurred. Control responses were evoked at a stimulus frequency of $0.5 \mathrm{~Hz}$. Changes in dendritic input resistance were tracked by periodically monitoring the antidromic action potential amplitude, because this signal is conducted passively to the recording site after its generation in the axon hillock (Furshpan and Furukawa, 1962; Faber and Korn, 1978).

Potentiating paradigms. To induce LTP, we applied a brief tetanizing train of six stimuli at $500 \mathrm{~Hz}$ (auditory stimuli in the range of $200-800 \mathrm{~Hz}$ maximally activate NVIII afferents projecting to the M-cell; Fay and Olsho, 1979) to the nerve once every $2 \mathrm{sec}$ for $\sim 4 \mathrm{~min}$. Tetanus intensity was adjusted to be suprathreshold such that the M-cell could initiate at least one orthodromic action potential per burst (Yang et al., 1990). For the dopamine-evoked potentiation, a second micropipette containing 10 mM dopamine (3-hydroxytyramine; Sigma, St. Louis, MO) dissolved in a vehicle solution [containing (in $\mathrm{mm}$ ): $130 \mathrm{NaCl}, 10 \mathrm{HEPES}$, and 1 ascorbic acid, $\mathrm{pH}$ 7.2] was positioned in the synaptic bed, and the amine was applied by pressure ejection (10-20 psi) for 1-3 min (the duration of application is indicated approximately by the width of the thick arrows in the figures). Reduction in the input resistance of the dopamine electrode during injection signaled successful ejection of the electrode contents. In control experiments a single application of the amine typically produced a saturating potentiation within 3-8 min. However, to confirm saturating potentiation or the lack thereof, we found that a second or third session of dopamine application was sometimes necessary, and no new perturbations were attempted until the evoked responses stabilized. Vehicle controls in which dopamine was omitted from the electrode did not affect M-cell responses in any way (data not shown). Stable intracellular recordings during experimentation are indicated by the constancy in membrane potential (typically -75 to $-83 \mathrm{mV}$ ). Experiments in which a potentiating paradigm either depressed or failed to enhance both components of the EPSP simultaneously by $\geq 2 \%$ of their control values by $\sim 10$ min after application were considered "nonpotentiating" and were excluded from the data for statistical comparison.

Voltage clamp. All recordings were made with the aid of an Axoclamp-2A amplifier (Axon Instruments, Foster City, CA). Intradendritic recordings in both current (bridge mode) and discontinuous singleelectrode voltage-clamp (SEVC; sampling rate 10-15 kHz) were obtained by using microelectrodes designed to have slightly lower tip resistance (4-7 $\mathrm{M} \Omega$ ) to minimize the settling times for voltages after current pulses and also to improve the current-passing ability and the overall recording stability during current injections. Although the large M-cell cannot be voltage-clamped fully, the space constant of the dendrite ( $\sim 250 \mu \mathrm{m}$; Faber and Korn, 1978) allows for an adequate space clamp of a substantial region of the dendrite receiving the synaptic input. However, the low input resistance of the M-cell $(\sim 200 \mathrm{~K} \Omega)$ and its electrotonic coupling to the afferents restrict the stability of the clamp when membrane potential is changed by $30 \mathrm{mV}$ or more from resting membrane potential, particularly with depolarizations, which activate voltage-dependent conductances pre- and postsynaptically. Care was taken to see that the EPSCs were stably reproducible, and measurements of the peak synaptic currents from baseline were made after they first were isolated from the leak currents produced by the same voltage steps without concurrent NVIII stimulation. In all voltage-clamp experiments we confirmed that EPSPs were similar in magnitude before and after voltage clamp.

Data analysis. Data were analyzed both on-line and after storage on a pulse code-modulated video recording system (Vetter 400, Regensburg, PA), using a Macintosh Quadra 950 with digitizing boards from National Instruments and homemade software. The percentages of potentiations for both electrotonic coupling potential and chemical EPSP refer to enhancements in their peak amplitudes measured from averaged responses to $10-15$ consecutive stimuli under control conditions and after a potentiating paradigm. Measurements used for statistical analysis were taken just before an experimental manipulation and 15-20 min after it, unless otherwise noted. Those experiments with unstable control baselines ( $\geq 10 \mathrm{~min}$ ) were not included. Statistical analysis was done with the built-in Microsoft Excel analysis toolpack (GarryMatter International, Cambridge, MA), and statistical significance of the difference between the means of two groups was determined by using two-tailed $z$ and $t$ tests or, where appropriate, ANOVA, followed separately by the Kolmogorov-Smirnov test. Also, these results ( $p$ values), unless indicated otherwise, apply to both the electrotonic coupling potential as well as the chemical EPSP. Paired-pulse facilitation (PPF) was estimated by using the expression: \% Facilitation $=\left[\left(\right.\right.$ Response $_{2}-$ Response $\left._{1}\right) /(\mathrm{Re}-$ sponse $\left.\left._{1}\right)\right] 100 \%$.

Drugs. Dopamine D1/5 receptor antagonist $\mathrm{R}^{(+)}-\mathrm{SCH}-23390$ hydrochloride $(50 \mu \mathrm{M})$ and the broad-spectrum dopamine receptor antagonist spiperone hydrochloride (100 $\mu \mathrm{M}$; Research Biochemicals, Natick, MA) were added to the superfusing medium just before the experiment. Care was taken to protect the Scherring compound from light.

The glutamate receptor antagonists DL-2-amino-5-phosphonovaleric acid (APV; Sigma) and bis(2-carboxypiperazine-4-yl) propyl-1phosphonic acid (CPP; Research Biochemicals), $50 \mu \mathrm{M}$ each, and 6-cyano-7-nitroquinoxaline-2,3-dione (CNQX; Cambridge Research Biochemicals, Cheshire, UK), $1 \mathrm{~mm}$, were all introduced through the superfusing medium. Because the M-cell lies $\sim 1.5 \mathrm{~mm}$ below the brain surface, the exact effective concentration of the drugs and the actual diffusion rates at the synaptic sites could not be determined accurately. Hence, drug concentrations were $\sim 10$-fold higher than those normally used in other systems. In addition, the compounds were given sufficient time to diff use to the synaptic regions, and the NVIII-evoked EPSPs and the antidromic spike height were monitored constantly until the magnitudes of the drug effects appeared to stabilize. Reversal of drug effects is constrained by the in situ nature of the preparation and therefore was considered unreliable. The protein kinase inhibitor $\mathrm{PKI}_{5-24}(900 \mu \mathrm{M}, 3$ $\mu \mathrm{l}$; Sigma) was suspended in a vehicle solution $(7 \mu \mathrm{l} ; 0.5 \mathrm{M} \mathrm{KCl}$ and 10 mM HEPES, $\mathrm{pH}$ 7.2) and pressure-injected into the dendrite through the recording electrode (10-20 psi). Likewise, the $\mathrm{Ca}^{2+}$ chelator BAPTA (20 mM; Sigma), dissolved in $2.5 \mathrm{M} \mathrm{KCl}$ and $10 \mathrm{~mm}$ HEPES, pH 7.2, also 

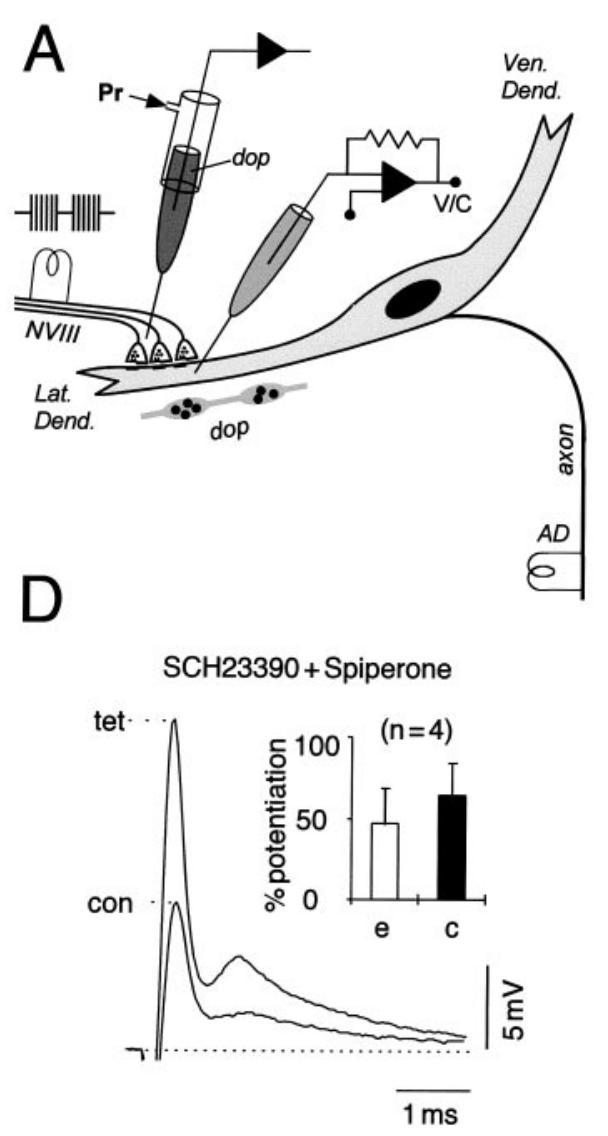
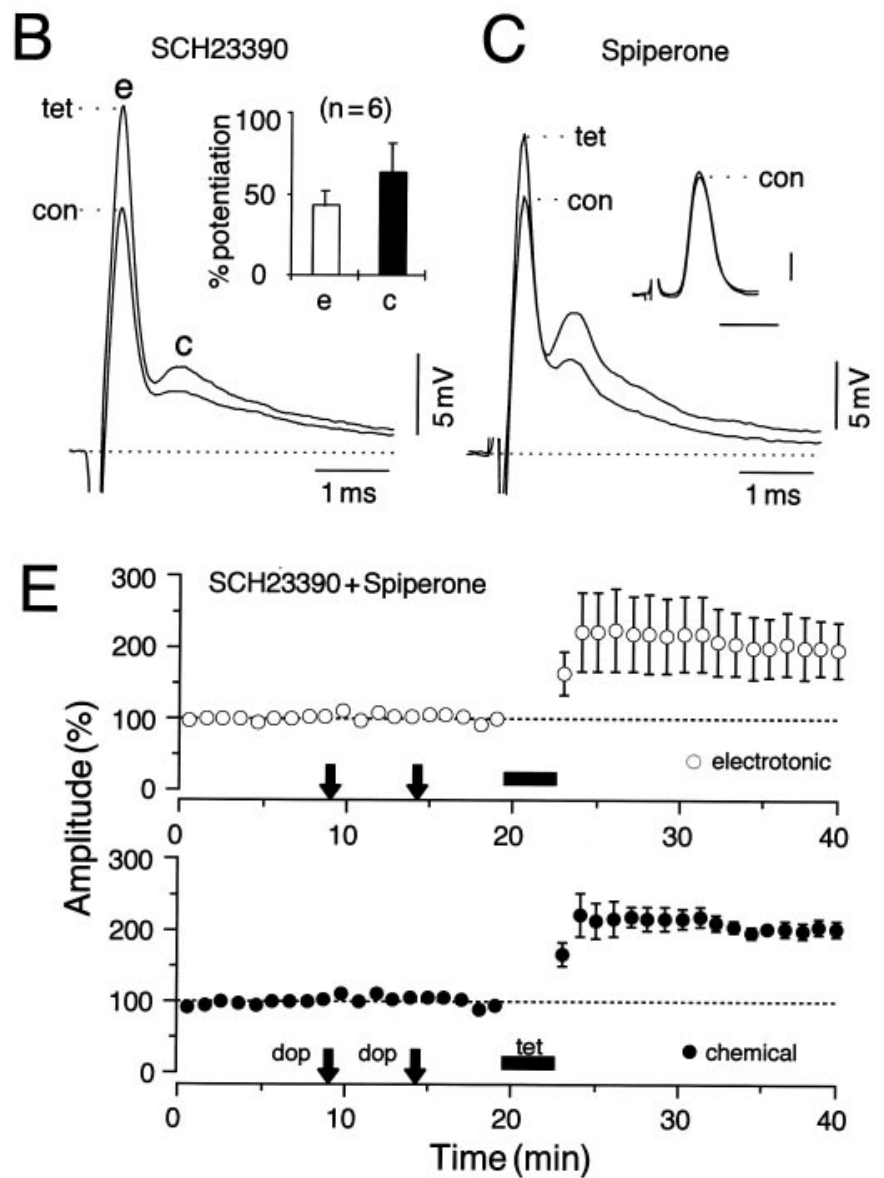

Figure 1. Experimental paradigms for potentiating eighth nerve synapses. $A$, Schematic of the neural circuit depicting intracellular voltage $(V)$ and current-clamp $(C)$ recording from the lateral dendrite (Lat Dend) of the Mauthner cell (M-cell). Antidromic $(A D)$ activation of the axon of the M-cell is used for identifying the cell. The test input is a single stimulus to the eighth nerve (NVIII). Potentiating paradigms are (1) tetanization of the NVIII with repeated brief high-frequency trains and (2) local application of $10 \mathrm{~mm}$ dopamine (dop) to the dendrite by pressure ejection or ionophoresis. Varicose fiber denotes dopaminergic innervation of the synaptic bed. $B-E$, LTP of excitatory transmission is induced in the presence of dopamine receptor antagonists. $B-D$, Data from experiments in which a tetanus was applied to NVIII after superfusion of the brain for at least 30 min with saline containing a selective antagonist of the D1/5 receptor SCH23390 $(50 \mu \mathrm{M}, B)$; spiperone hydrochloride $(100 \mu \mathrm{M}, C)$, a broad-spectrum dopamine receptor antagonist; and a combination of SCH23390 and spiperone $(D)$. Traces are superimposed averaged $(n=5)$ intradendritic recordings of M-cell responses to NVIII stimulation before (con) and at least $15 \mathrm{~min}$ after tetanization (tet). Insets: $B, D$, Bar plots from six and four experiments, respectively, of mean $( \pm$ SEM) percentage potentiations of the electrotonic coupling potential $(e)$ and chemical EPSP $(c) ; C$, passively conducted antidromic action potentials recorded during the same periods. Calibrations are as for synaptic responses. $E$, Time course data from control experiments in which the brain initially was superfused with the dopamine receptor antagonist cocktail and the amine was applied to the dendrite before tetanization, showing that, in the presence of the antagonists, dopamine is ineffective whereas tetanization still produces a robust and persistent potentiation. Shown is a plot of the data pooled from four experiments of averaged ( \pm SEM) normalized amplitudes (ordinate) of the electrotonic coupling potential (open circles) and the chemical EPSP ( filled circles) versus time (abscissa), with dopamine (dop) and the tetanus (tet) applied during the periods indicated. For both, 100\% equals the ensemble average of all of the corresponding control values. Note that the error bars for the control values are concealed because they smaller than the size of the symbols used.

was injected by using pressure $(10-20 \mathrm{psi})$ and iontophoretic pulses $(-15$ to $-20 \mathrm{nA}, \sim 500 \mathrm{msec}$ ) for $\sim 3-4 \mathrm{~min}$.

\section{RESULTS}

\section{General properties of mixed NVIII synapses}

Stimulation of NVIII evokes a characteristic biphasic response (Furshpan, 1964) in the M-cell (Fig. 1B) consisting of a fast electrotonic coupling potential that is mediated by current flow through gap junctions and a slower chemical EPSP resulting from the release of the neurotransmitter glutamate (Lin and Faber, 1988; Wolszon and Faber, 1988; Wolszon et al., 1997). Yang et al. (1990) showed that, after NVIII tetanization, both components of the synaptic response are enhanced relative to their control amplitudes. In the present study the LTP occurred in $\sim 70 \%$ of all trials when the tetanus was applied first (16 of 23 experiments), the potentiation averaging $44 \pm 7 \%$ (SEM) for the electrotonic coupling potential and $69 \pm 21 \%$ (SEM) for the chemical EPSP in one control series (7 of 10 experiments). Because input resistance, measured indirectly from the size of the antidromic (AD) action potential of the M-cell, and the extracellular presynaptic volley remain constant (Yang et al., 1990), the LTP is synaptic in nature, and it lasts for as long as stable intracellular recording can be maintained reliably (up to $4 \mathrm{hr}$ ).

Pereda et al. (1992, 1994) showed previously that pressure application of dopamine (10 $\mathrm{mm}$ in the pipette) in the vicinity of the lateral dendrite produces a slowly developing but persistent potentiation of both components of the NVIII-evoked synaptic response. In the present study this potentiation averaged $37 \pm 7 \%$ 
(SEM) for the electrotonic coupling potential and $38 \pm 6 \%$ (SEM) for the chemical EPSP $(p<0.01)$ and was manifest in all experiments $(n=6)$ in a control series. In both cases these potentiations are less than those induced by eighth nerve tetani. It is possible that tetanization affects a larger population of synapses than does dopamine. For example, the amine might not have reached all afferent synapses subjected to LTP. However, 3-5 $\mu \mathrm{l}$ of dopamine was applied in close proximity to the synaptic input at an initial concentration (10 mM) sufficient to compensate for volume dilution. The low molecular weight of the amine (189.6) ensured that diffusion was not a major barrier to its uniform dispersion. Finally, the dopamine effect generally took 3-8 min to reach a saturating level of potentiation. These considerations suggest dopamine had access to all studied synapses, consistent with the result that no further enhancements were seen after subsequent applications of the amine. As with previous studies, the antidromic action potential in the same series decreased by an average of $6 \%$ after the application of dopmaine, although this decrement was not statistically significant $(p>0.5)$.

PPF of the chemical EPSP at the NVIII-M-cell synapse is primarily a presynaptic phenomenon (Lin and Faber, 1988). Therefore, a reduction in PPF after potentiation usually is taken as an indicator of a presynaptic change in strength of a synapse (McNaughton, 1982; Zalutsky and Nicoll, 1991). Pereda et al. (1994) previously suggested that the amine acts postsynaptically because there is no change in PPF after the DEP. We confirmed this result, with the average PPF after dopamine application $(72 \pm 12 \% ; n=5)$ being equivalent to that in the control $(70 \pm$ $15 \%)$. Furthermore, when a similar computation was made for tetanus-induced LTP, there was no significant difference between the average PPFs before $(39 \pm 4 \%)$ and after tetanization $(41 \pm$ $4 \% ; n=5)$. Note that PPF ratios for the dopamine and tetanus controls in these two series are different. The underlying explanation is unclear, although we did note that the amplitude of the initial response for dopamine experiments $(4.5 \mathrm{mV})$ averaged lower than that for the tetanus $(6 \mathrm{mV})$. Thus, although retrograde factors cannot be ruled out fully, both LTP and DEP appear to be expressed postsynaptically.

\section{LTP is not attributable to dopamine release}

Given the presence of dopaminergic fibers close to the dendrite and the terminals of the NVIII afferents, it is conceivable that the tetanus could exert its potentiation by transsynaptically exciting dopaminergic neurons, which then would release the modulator into the synaptic bed. To test this hypothesis, we first tetanized the eighth nerve in the presence of the selective D1/D5 receptor antagonist $\mathrm{SCH} 23390(50 \mu \mathrm{M})$, which is known to block the dopamine effect (Pereda et al., 1992; Silva et al., 1995). The compound did not prevent either the induction $(100 \% ; n=6)$ or maintenance of LTP, as shown in Figure $1 B$. Potentiations averaged $43 \pm 9 \%$ (SEM) for the electrotonic coupling potential and $64 \pm 18 \%$ (SEM) for the chemical EPSP and were comparable in magnitude to LTP controls $(p>0.05)$. This result rules out the possibility that the observed LTP is attributable to a direct action of released dopamine. However, it is possible that LTP induction involves the action of dopamine on other receptors. Therefore, to test for the possible involvement of the other dopamine receptor subtypes in tetanus-induced LTP and to prevent the activation of dopamine receptors in general, we used a broad-spectrum dopamine receptor antagonist, spiperone hydrochloride $(100 \mu \mathrm{M})$, alone (Fig. 1C) and in combination with SCH23390 (Fig. 1D,E). In neither case were the potentiations evoked by tetanization blocked or reduced. In four of four experiments in the presence of the cocktail, we observed enhancements; they averaged $47 \pm$ $22 \%$ (SEM) for the electrotonic coupling potential and $64 \pm 20 \%$ (SEM) for the chemical EPSP (see inset, Fig. 1D), and the corresponding increments in the example of Figure $1 C$ were $\sim 26$ and $\sim 59 \%$, respectively. These potentiations are comparable to those in the control LTP experiments. Dopamine was applied in the presence of the receptor antagonist cocktail before tetanization in four additional experiments. The pooled results in Figure $1 E$ show that DEP was blocked effectively by the antagonists, as expected, whereas tetanization still produced a robust potentiation of both components. Specifically, the synaptic responses were $100 \%(e)$ and $93 \%(c)$ of their averaged control values $\sim 10 \mathrm{~min}$ $(p>0.01)$ after the first dopamine application, and there also was no effect of a second exposure to dopamine. The subsequent tetanization produced potentiations in all four experiments. The mean percentage increases $\sim 10$ min after tetanization (125 and $119 \%$ for the coupling potential and chemical EPSP, respectively) were surprisingly larger than either LTP controls or cocktail experiments in which the amine was excluded (Fig. 1D), although this difference did not reach statistical significance. We conclude from these experiments that the induction of tetanus-evoked potentiation does not require dopamine release.

\section{Interactions between the potentiating pathways}

To test for intracellular convergence and to determine whether the two potentiating pathways shared a common expression mechanism, we examined the interactions between the paradigms by applying them sequentially, repeating the initial manipulation a second time, to guarantee that its effect was maximal. The responses in Figure $2 A 1$ show averaged $(n=15)$ intradendritic recordings from such an experiment. The time course of potentiation in Figure $2 A 2$ shows that in this experiment both components were enhanced by $\sim 30 \%$ after dopamine and by $\sim 60 \%$ of their averaged control values $(100 \%)$ after tetanization. Note that the second application of dopamine was ineffective, confirming that it had produced a saturating effect and that the passively conducted antidromic action potential (see inset, Fig. 2A1) remained constant throughout the recording session. Figure 2, B1 and $B 2$, illustrates an example in which the sequence of the potentiating paradigms was reversed. After tetanus-induced LTP, dopamine did not produce any further enhancements, and in this experiment slight reductions in the electrotonic coupling potential $(3 \%)$ and in the chemical EPSP $(9 \%)$ actually occurred during application of the amine. This effect was not observed in other experiments of this series. Also, the extra tetani used in the tetanus-dopamine series to guarantee saturating LTPs did not contribute significantly to the final enhancement achieved before dopamine application ( $p>0.05 ; n=5)$. In fact, in two of the five experiments belonging to this series a second tetanus actually reduced the enhancements produced by the first by $\sim 20 \%$ (data not shown).

Results of the statistical analysis of the interaction paradigms and the corresponding controls are summarized in Figure $3 A-C$. First, the mean potentiations produced by a tetanus (only those 7 of 10 experiments in which the tetanus produced a potentiation were included in this analysis) are larger than those evoked by dopamine (Fig. 3A). Tetanus-induced enhancements, when normalized to the mean DEPs $(100 \%)$, are larger by $\sim 19 \%$ for the electrotonic coupling potential $(0.05<p<0.08)$ and by $\sim 82 \%$ for the chemical EPSP $(p<0.05)$. Although the two components of the synaptic response were not always potentiated by the same 

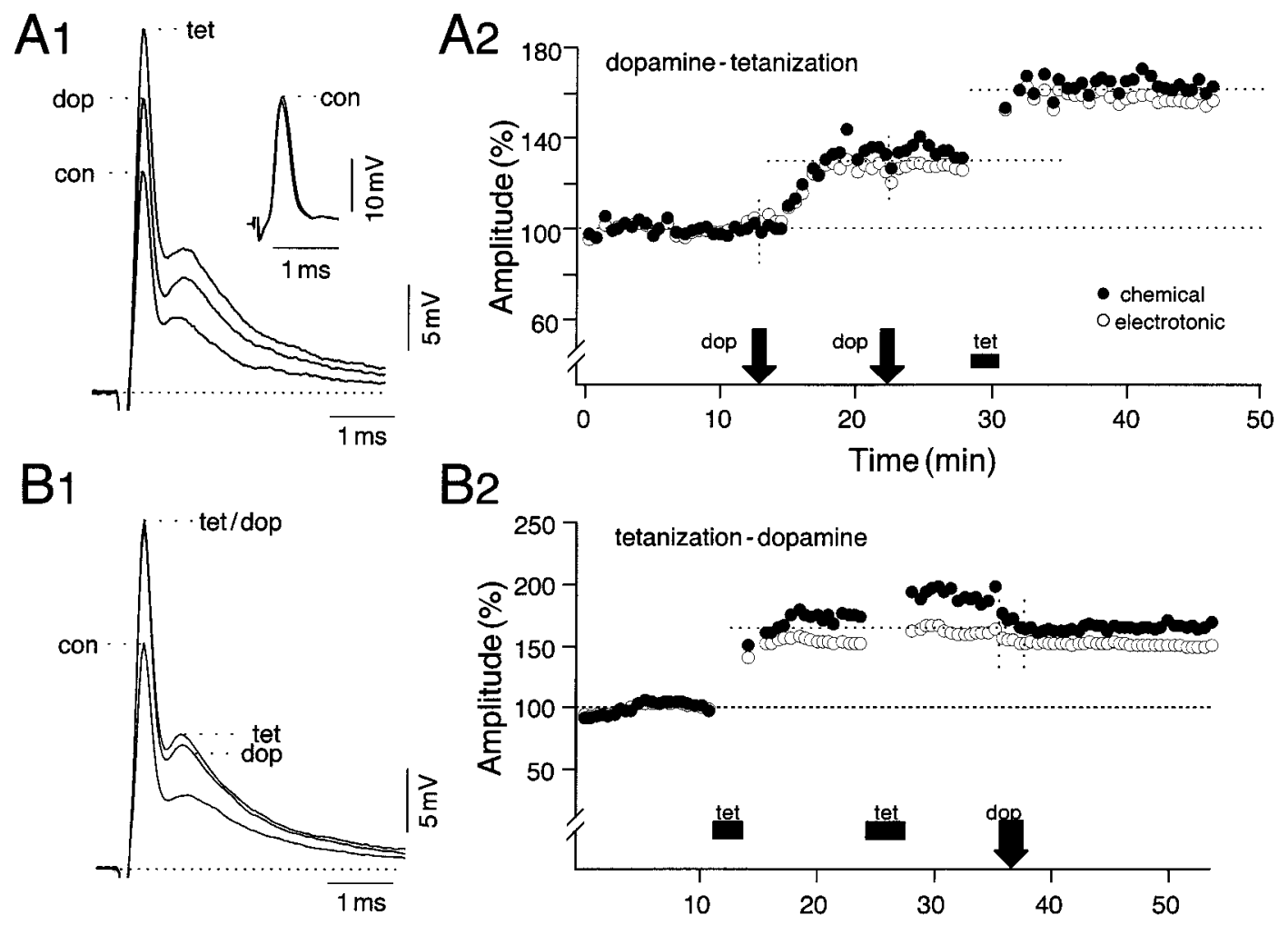

B2

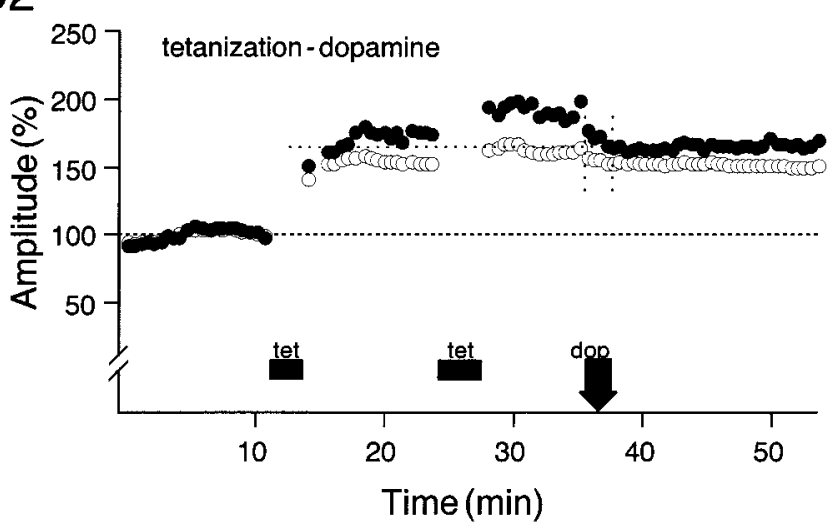

Figure 2. Interaction experiments demonstrating differential effects of dopamine application before and after NVIII tetanization. $A 1, A 2$, When dopamine was applied first, tetanization produced an additional potentiation of the mixed synaptic response. The dashed line represents the baseline for peak amplitude measurements. $A 1$, Superimposed averaged $(n=15)$ intradendritic recordings of the M-cell response to NVIII stimulation before (con) after application of dopamine ( $d o p)$ and $\sim 10 \mathrm{~min}$ after tetanization (tet). A1, Inset, Averaged antidromic action potentials recorded during the same periods. A2, Corresponding time course of changes in the mean normalized amplitudes of the electrotonic coupling potential (open circles) and the chemical EPSP ( filled circles), with dopamine (arrow) and tetanus (bar) applied during the indicated periods. For both, $100 \%$ equals the average of all control values, and each point is an average of 15 consecutive responses evoked at $0.5 \mathrm{~Hz}$. Note that dopamine was applied twice to confirm that it had produced a saturating effect. $B 1, B 2$, When the sequence of manipulations was reversed, with tetanization preceding dopamine, the latter was ineffective, and further potentiation was occluded. $B 2$, A second tetanus was used at an $\sim 10$ min interval after the first to guarantee maximal potentiation; in this experiment there was a slight decrease in the chemically mediated EPSP after dopamine application. The duration of treatments is coarsely indicated by the width of their respective icons on the time course plots.

amounts by either paradigm, on average the tetanus enhanced the chemical EPSP more than the electrotonic coupling potential $(p>0.05 ; n=7)$, and dopamine affected the two equally. Second, when dopamine and tetanus were applied sequentially, the net synaptic enhancements produced by the two paradigms together were significantly larger $(p<0.05 ; n=6)$ than those evoked by dopamine alone (Fig. $3 B$ ). Also, the tetanus induced LTP in all six experiments. In contrast, the difference between the potentiations after an initial tetanization and those after the subsequent addition of dopamine is not statistically significant (Fig. $3 C ; p>0.05 ; n=5$ ).

If the potentiations were attributable to independent induction and expression mechanisms, they would be additive. The results shown in Figure $3 C$, in which a previous tetanus occluded any added effect of dopamine, argue against that possibility. In this series, in which multiple tetani were used to ensure saturating effects, the mean potentiations in coupling and chemical transmission caused by the tetani alone $[60 \pm 13 \%(e)$ and $58 \pm 16 \%$ (c); $n=5$ of 7 experiments] were not statistically different from the LTP controls (Fig. $3 C$ vs $A ; p>0.05 ; n=5$ ). Also, when we compared the final potentiations in the dopamine-tetanus series of Figure $3 B[63 \pm 11 \%(e) ; 97 \pm 17 \%(c) ; n=6 ; 100 \%$ induction rate] with the LTP controls of Figure $3 A[44 \pm 7 \%(e) ; 69 \pm 21 \%$ $(c) ; n=7]$, the differences were not statistically significant $(p>$ 0.1 , although the means were greater for the combined treatment. To ensure that the results of these statistical tests were not biased by the assumption of an underlying distribution, we also verified their level of significance with a nonparametric Kolmogorov-Smirnov test ( $p=0.28$ and 0.29 for $e$ and $c$, respectively). The results thus indicate that an initial potentiation either fully or partially occludes the enhancement of synaptic strength that otherwise would be the consequence of the other manipulation, suggesting that these two processes share a common intermediary step or target.

\section{Does dopamine influence LTP induction?}

In the hippocampal-prefrontal pathway, dopamine enhances excitatory transmission by facilitating the induction of LTP (Jay et al., 1996). We have noted that, as with other systems, the N V III tetanizing paradigm does not always induce LTP, our overall success rate being $\sim 70-75 \%$. For example, in the series illustrated in Figure $3 C$, the initial tetanus failed to produce LTP in two of eight experiments. In contrast, when dopamine preceded the tetanus (Fig. 3B), the success rate for LTP was $100 \%$ (six of 

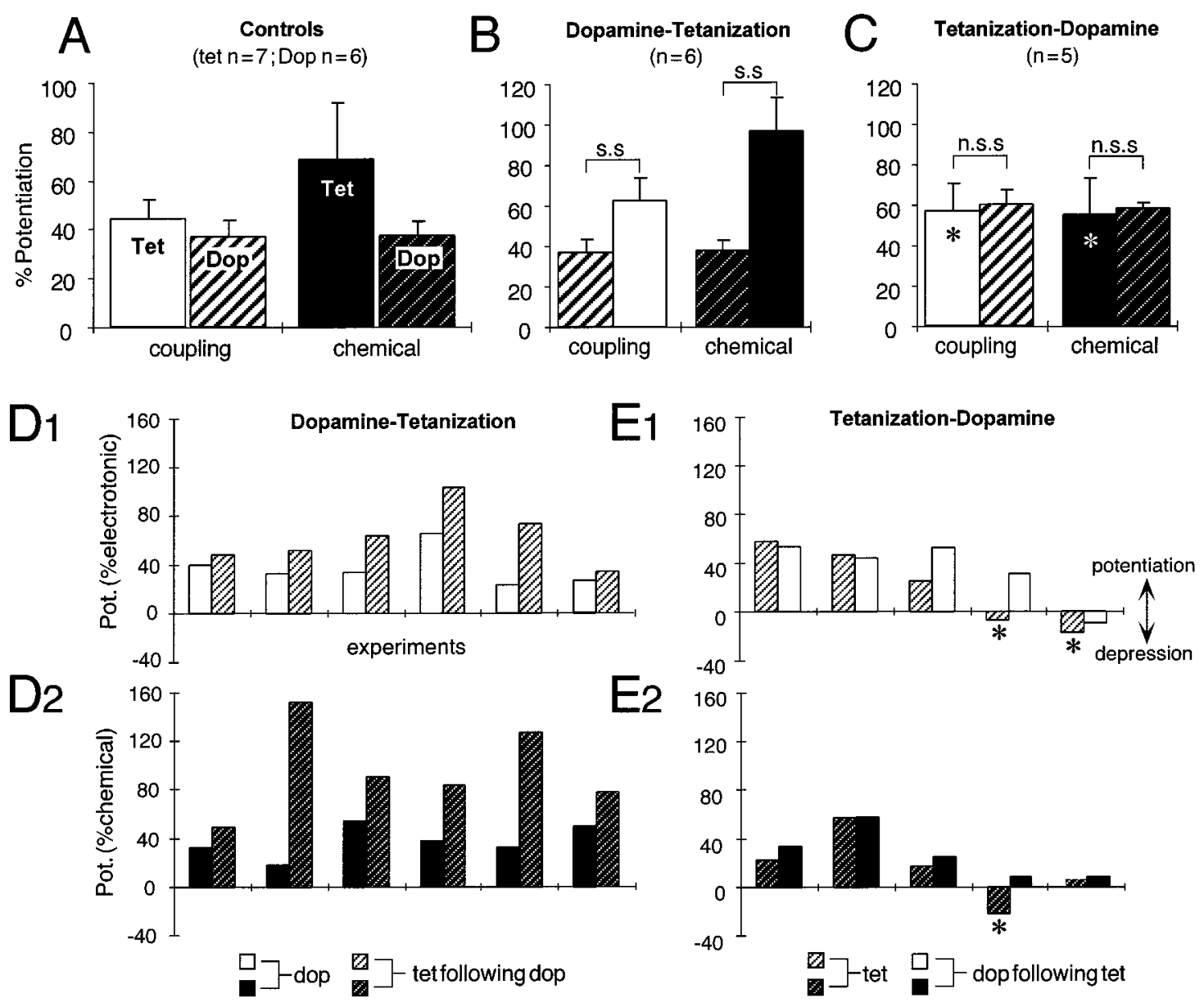

Figure 3. Statistical analysis of occlusion experiments. $A-C$, Bar plots representing the mean $( \pm \mathrm{SEM})$ percentage potentiations of the electrotonic coupling potential (open bars) and the chemical EPSP (filled bars) under different experimental protocols. $A$, Control experiments in which enhancements of synaptic transmission were induced by either a single episode of NVIII tetanization (Tet) or the application of dopamine (Dop; hatched bars). $B, C$, Data from interaction experiments. In each histogram the potentiations are referenced to the averaged control response before any manipulation. In $B$, for both the coupling potential and the chemical EPSP, the dopamine-evoked potentiation was significantly (s.s) different $(p<0.05$; $n=6$; paired $t$ test) from the total potentiation after tetanization in the same series of experiments. In contrast, in $C$, the difference between the potentiation after tetanization and that after adding dopamine as well was not statistically significant (n.s.s) $(p>0.05 ; n=5 ;$ paired $t$ test). Asterisks in $C$ indicate that multiple tetani (3) were used at $\sim 10 \mathrm{~min}$ intervals before dopamine application. The mean $(\mu)$ potentiations $( \pm$ SEM) of the electrotonic coupling potential $(e)$ and the chemical EPSP $(c)$ in control experiments in $A[\mu(e)=44 \pm 7 \% ; \mu(c)=67 \pm 21 \% ; n=7]$ and the final potentiations after tetanization in the dopamine-tetanus series in $B[\mu(e)=63 \pm 11 \% ; \mu(c)=97 \pm 17 \% ; n=6]$ did not differ significantly $(p>0.1$; Kolmogorov-Smirnov test). $D, E$, Data from individual interaction experiments suggesting that dopamine influences the effectiveness of tetanus-induced LTP. Shown are results from a random series of experiments (abscissa) in which the order of manipulations was decided by a coin toss. D1, D2, E1, E2, Bar plots of the percentage of potentiations (ordinate) of the electrotonic coupling potential $(D 1, E 1)$ and the chemical EPSP (D2, E2) in which a single episode of NVIII tetanization was preceded by the application of dopamine $(D 1, D 2)$ or was followed instead by the amine $(E 1, E 2)$. D1, D2, Tetanization always produced an enhancement of synaptic transmission if it was preceded by dopamine. E1, E2, Tetanization that was applied first produced a depression (asterisk) in two of the illustrated cases. Note also that, when tetanization produced a depression, the amine still enhanced the synaptic responses. All changes in synaptic transmission are referenced to their corresponding experimental control values.

six initial trials). To explore further the possibility that the amine facilitates LTP induction, we determined the order of the manipulations by a coin toss in a random series of 11 experiments. The results indicated that tetanization always produced potentiation when preceded by dopamine (Fig. 3D1,D2; six of six trials) in contrast to the observations that an initial tetanus produced LTP in only three of five trials (e.g., Fig. 3E1,E2) in this series of experiments. The tetanus was applied 12-15 min after the application of the amine, at which time there was a stable DEP. Data from these experiments imply that dopamine does, indeed, influence whether a tetanus triggers LTP, presumably by priming the system postsynaptically for potentiation rather than depression. Thus, overall, when tetanization was applied first, it produced
LTP in 16 of 23 experiments, whereas the success rate was $100 \%$ if either dopamine application (12 of 12 cases) or a dopamine antagonist (12 of 12 trials) preceded the tetanus.

When the reverse experiment was performed, i.e., tetanization first, dopamine was, as expected, most effective if the tetanization produced smaller potentiations or depression. Note that all experiments in this series used a single episode of tetanization, i.e., there was no test for saturation. In two of the five cases illustrated in Figure 3, E1 and E2, tetanization actually produced a depression of either the electrotonic coupling potential and/or the chemical EPSP, and dopamine either reduced the depression or converted it into a potentiation. The fact that dopamine can cause a reversal of synaptic depression in this system indicates that the 

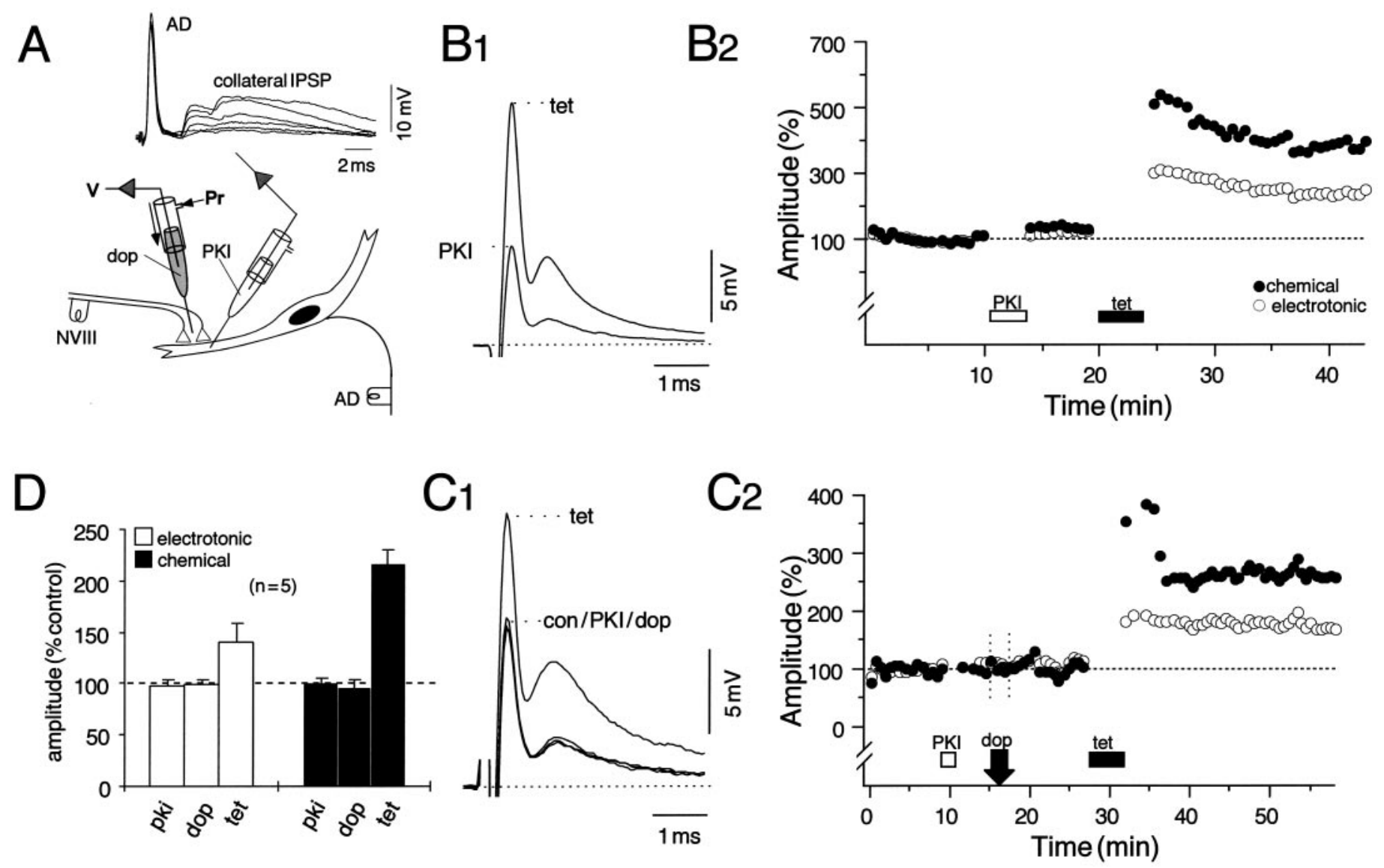

Figure 4. LTP does not require the activation of cAMP-dependent protein kinase (PKA). $A$, Schematic of the experimental arrangement for intradendritic pressure injections (below) with superimposed consecutive traces of the passively conducted antidromic action potentials $(A D)$ and the chloride-dependent collateral IPSP recorded during the injections (above). The transient increase in the IPSP indicates successful pressure injection of a solution containing $900 \mu \mathrm{m}$ of the cAMP-dependent protein kinase inhibitor (PKI). B1, B2, NVIII tetanization in the presence of PKI still produces a robust and persistent potentiation. $B 1$, Superimposed averaged $(n=15)$ intradendritic recordings of the M-cell response to NVIII stimulation after injection of the inhibitor (PKI) and $\sim 10$ min after tetanization (tet). B2, Plot of normalized amplitudes (ordinate) of the electrotonic coupling potential (open circles) and the chemical EPSP ( filled circles) versus time (abscissa), with PKI and tetanus applied during the indicated periods. In this and subsequent figures, $100 \%$ equals the mean of all of the corresponding control (con) values, and each point is an average of at least 15 response amplitudes evoked at a stimulus rate of $0.5 \mathrm{~Hz}$. $C 1, C 2$, To ensure that the injected peptide was active, we applied dopamine (dop) to the dendrite through an extracellular microelectrode before tetanization. Shown are averages of the response to NV III stimulation $(C 1)$ and the time course of changes in the electrotonic coupling and chemical PSP (C2) after the indicated sequence of manipulations. Note that, as in $B 2$, the chemical EPSP is potentiated more than the coupling potential. $D$, Pooled data $(n=5)$ demonstrating that the inhibitor blocks dopamine-evoked potentiation yet spares tetanus-induced LTP. The bar plots represent changes in the mean amplitude (\% control) and SEM (error bars) of the coupling potential (open bars) and the chemical EPSP ( filled bars) after PKI, dopamine, and tetanization. Measurement samples in this and subsequent bar plots were taken from the steady-state regions of the time courses, typically $10-15$ min after a perturbation. After tetanization, the mean $(\mu)$ potentiations $( \pm$ SEM $)$ of the chemical EPSP $[\mu(c)=$ $116 \pm 14 \%]$ are consistently larger than the coupling potential $[\mu(e)=40 \pm 18 \%]$ in this series, but not statistically different from controls $(p>0.05$; $n=7)$.

occlusion produced by LTP is a direct consequence of the potentiating mechanism and not of the tetanus per se.

To examine the influence of the amine on the magnitude of tetanus-induced potentiation in this series, we compared the final aggregate potentiations in Figure $3, D 1$ and $D 2(n=6)$, with either (1) tetanus control experiments (Fig. $3 A$ ) combined with tetanus-induced enhancements in Figure $3 C(n=12)$ or $(2)$ tetanus controls combined with the initial potentiations in Figure $3, E 1$ and $E 2[n($ electrotonic $)=10 ; n($ chemical $)=11]$; there were no statistical differences $(p>0.05)$ for either component of the response. However, because the EPSP is evoked by the activation of a heterogeneous population of afferent synapses, with different initial states and responsiveness to tetanization (Pereda et al., 1998 a,b), we prefer to focus on changes in the incidence of LTP rather than its magnitude.

\section{Does LTP require the activation of PKA?}

Dopamine-induced potentiation of the NVIII-evoked biphasic synaptic response in the M-cell lateral dendrite is mediated postsynaptically via the activation of a cAMP-dependent protein kinase, PKA (Pereda et al., 1992). The dopamine effect is blocked when $\mathrm{PKI}_{5-24}$, a highly specific inhibitor of the catalytic subunit of the kinase, is injected into the cell (Pereda et al., 1994). We therefore injected $\mathrm{PKI}_{5-24}$ intradendritically before attempting to induce LTP. Successful injections were signaled by large transient increases in the late collateral IPSP of the antidromically evoked action potentials (Fig. 4A) caused by a depolarizing shift in the chloride equilibrium potential of the M-cell, which is normally close to the resting potential $(-80 \mathrm{mV})$. Afferent tetanization in the presence of intracellular PKI still induces a robust and sus- 
tained LTP of the synaptic responses, as shown in Figure 4, B1 and B2. In eight experiments, all of which exhibited LTP, the potentiations averaged $45 \pm 21 \%(\mathrm{SEM})$ for the electrotonic coupling potential $(e)$, and $65 \pm 32 \%$ (SEM) for the chemical EPSP $(c) \sim 5$ min after the tetanus and stabilized at $35 \pm 18 \%$ (SEM) and $47 \pm 29 \%$ (SEM), respectively, at $\sim 10 \mathrm{~min}$ after induction. The antidromically evoked action potential (AD) remained unaltered in the same series (mean $=101 \pm 4 \%$ of control). The illustrated effect represents one of the largest enhancements observed (144\% in $e$ and $221 \%$ in $c$ ) in this series, and the plot of the response amplitudes versus time (Fig. 4B2) shows that injection of the inhibitor itself did not modify the synaptic responses $(p>0.1 ; n=14)$, as was also the case with the vehicle carrying the peptide (data not shown). In five additional experiments, dopamine was applied after postsynaptic injection of PKI and before NVIII tetanization to confirm the efficacy of the inhibitor. Figure 4,C1 and $C 2$, represents an experiment taken from this series and demonstrates that DEP was blocked effectively in the presence of PKI ( $p>0.05 ; n=5)$ and that, again, tetanus induced LTP, as in other experiments in this series (five of five trials). The pooled data from these experiments are summarized by the bar plots (Fig. $4 D$ ) depicting changes in the mean amplitudes of the coupling potential and the chemical EPSP after PKI, dopamine, and tetanization. Responses averaged 99\% (e) and $102 \%(c)$ of their mean control amplitudes after the injection of PKI and averaged 101\% (e) and 94\% (c) 10 min after application of the amine. Although the DEPs in this series were either significantly smaller than dopamine controls $(p<$ $0.01 ; n=6$ ) or absent altogether, tetanus-induced potentiations in the same experiments were robust $(p<0.05)$, averaging $40 \pm$ $18 \%$ (SEM) for the coupling potential and $116 \pm 14 \%$ (SEM) for the chemical EPSP, and they persisted throughout the recording sessions. The enhancements in the chemical component after tetanization were larger than those in the electrotonic coupling potential in a majority of this set of experiments, and that was also the case for LTP controls [44 $\pm 8 \%(e) ; 69 \pm 23 \%(c)$ ], with there being no statistical difference between the two conditions $(p>0.1 ; n=7)$. These results allow the conclusion that induction of LTP via tetanization does not require the activation of PKA.

\section{Does dopamine-evoked potentiation involve elevated intracellular $\mathrm{Ca}^{2+}$ ?}

An increase in intracellular $\mathrm{Ca}^{2+}$ is the primary event that underlies the induction of LTP in the M-cell system (Yang et al., 1990; Pereda and Faber, 1996). Although its role in the dopamine-mediated enhancements has remained unexplored, the effects of the amine in other systems do involve intracellular biochemical cascades dependent on $\mathrm{Ca}^{2+}$ (Civelli et al., 1993).

As with tetanus-induced LTP (Yang et al., 1990), the possible role of $\mathrm{Ca}^{2+}$ in the dopamine-evoked potentiation was explored by means of postsynaptic intradendritic injections of the fast $\mathrm{Ca}^{2+}$ chelator BAPTA. In two preliminary experiments in which the amine first was applied to the dendrite after intracellular injection of $20 \mathrm{~mm}$ BAPTA, dopamine still produced potentiations of both components of the response, averaging $35 \%$ for the coupling potential $(e)$ and $45 \%$ for the chemical EPSP $(c)$. In the example illustrated in Figure 5, $A 1$ and $A 2$, the potentiations measured $53 \%(e)$ and $50 \%(c)$, respectively, $\sim 10 \mathrm{~min}$ after dopamine application, and a second injection of BAPTA did not alter the responses. Because these experiments did not demonstrate that the BAPTA injection was effective, a second BAPTA series involved an initial tetanization in an attempt to induce
LTP. As shown in Figure 5, B1 and B2, the tetanus failed to produce any potentiation, whereas dopamine subsequently evoked robust and persistent enhancements of both components of the synaptic response. Specifically, in six experiments the dopamine-evoked potentiations after tetanization averaged $24 \pm$ $15 \%$ (SEM) for the electrotonic coupling potential $(e)$ and $47 \pm$ $14 \%$ (SEM) for the chemical EPSP (c), and these enhancements were statistically comparable to DEP controls (37 $\pm 7 \%$ and $38 \pm$ $6 \% ; p>0.1 ; n=6)$. In contrast, the changes in both components after initial tetanization in the same series averaged $5 \pm 5 \%$ (SEM) and $10 \pm 8 \%$ (SEM), respectively, values significantly smaller than those for LTP controls $(p<0.05 ; n=7$; there was a true potentiation in only one experiment). That is, BAPTA effectively blocked tetanus-induced LTPs in these and other control experiments (Fig. $5 D$ ). The bar plots in Figure $5 C$ summarize changes in the mean amplitudes of both components of the synaptic response, normalized to their corresponding averaged control values, which follow the sequence of BAPTA, tetanus, and dopamine.

A consistent finding throughout the BAPTA experiments was a reduction in the amplitude of the chemical EPSP immediately after postsynaptic injection of the chelator. Although the coupling potential remained unaffected in large part, the mean amplitude of the chemical EPSP was reduced by $12 \pm 7 \%$, with the example illustrated in Figure 5B2 representing the largest reduction $(\sim 30 \%)$ observed. Although these decrements did not reach the level of statistical significance ( $p=0.08, n=6 ; t$ test), they nonetheless were manifest in five of the six experiments described here. This effect may perhaps be explained on the basis of BAPTA lowering the free $\mathrm{Ca}^{2+}$ concentration in the cytoplasm and thereby disrupting ongoing $\mathrm{Ca}^{2+}$-dependent signal transduction mechanisms. Regardless, the above results indicate that the dopamine-evoked potentiations in this system are, in contrast to LTP, not critically dependent on an elevated intracellular $\mathrm{Ca}^{2+}$ concentration.

\section{Dopamine enhances the AMPAR-mediated component of the chemical EPSP}

In the M-cell the chemically mediated EPSP evoked by NVIII stimulation is composed of both glutamatergic AMPA and NMDA receptor-mediated components that may be dissected pharmacologically (Wolszon and Faber, 1988; Wolszon et al., 1997). Tetanus-induced potentiation of these synapses results from the progressive activation of the NMDA receptors at these junctions because superfusion of the brain with saline containing the NMDA receptor-specific antagonists, APV and CPP (50 $\mu \mathrm{M}$ each), blocks enhancement of both components of the mixed response (Yang et al., 1990). In the example illustrated in Figure 6, $A 1$ and $A 2$, although there was no persistent potentiation of chemical transmission, the electrotonic coupling potential was, in fact, depressed by $\sim 25 \%$ after the tetanus. To determine whether NMDA receptor activation also contributes to the dopamineevoked potentiation, we applied the amine in the presence of APV/CPP. As illustrated in Figure 6, B1 and B2, after APV/CPP had blocked the NMDAR component of the EPSP, dopamine still produced modest potentiations of the responses. In this example, brief dopamine pulses were used, and the second set evoked a saturated DEP, as indicated by the effectiveness of the third group. The inset of Figure $6 B 1$ summarizes results from five experiments in which potentiation, found in each case, averaged $22 \pm 7 \%(\mathrm{SEM})$ and $36 \pm 8 \%$ (SEM) for the coupling potential and the chemical EPSP, respectively. Furthermore, these en- 

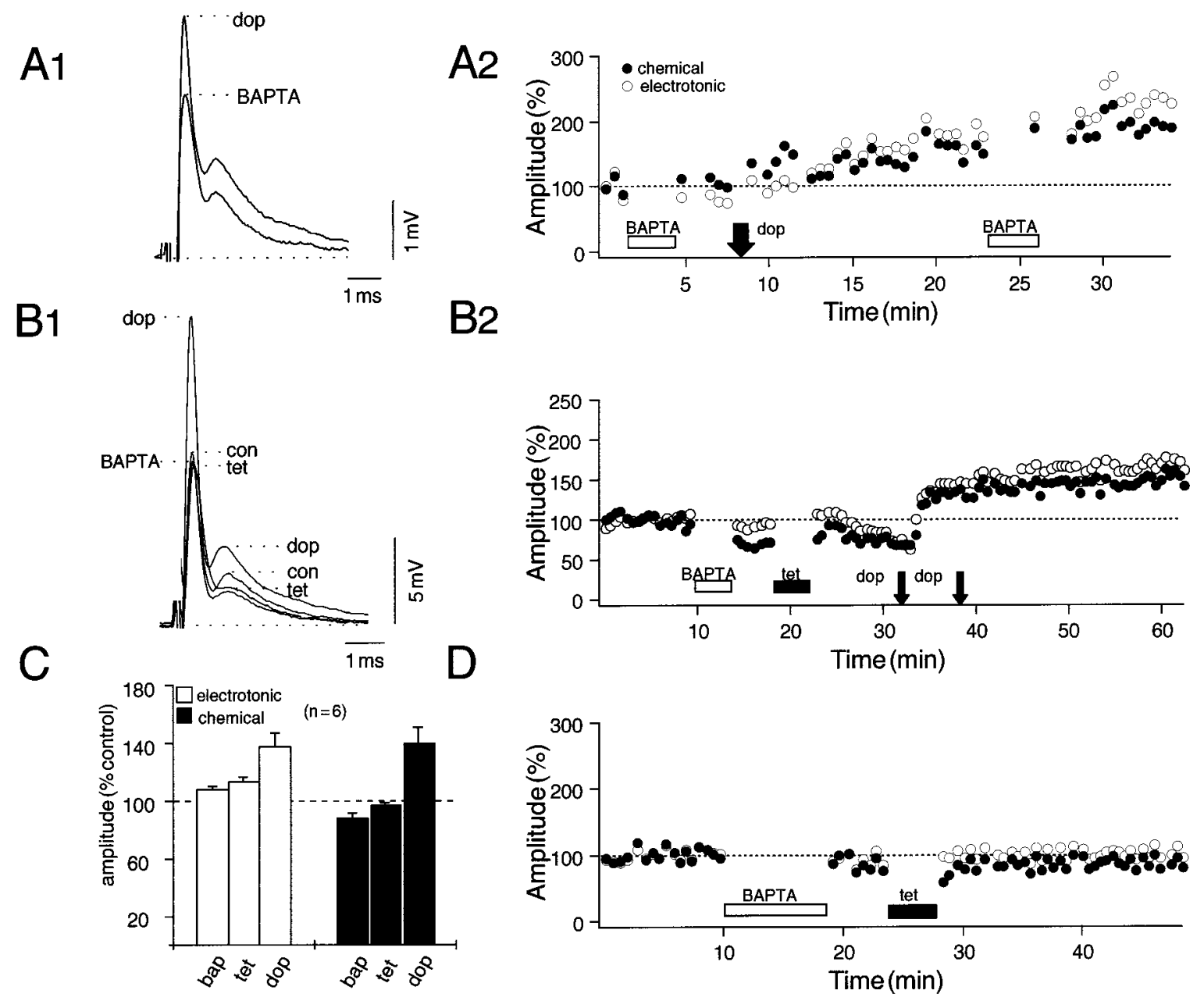

Figure 5. Postsynaptic BAPTA injections reveal the differential role of calcium in the induction of tetanus and dopamine-evoked potentiations. The experimental arrangement is as in Figure $1 A . A 1, A 2$, Data from an experiment in which dopamine (dop) was applied locally after intracellular injection of BAPTA $(20 \mathrm{mM})$. A1, Superimposed averaged $(n=15)$ intradendritic recordings of the NVIII response in the presence of BAPTA before and after the application of dopamine. A2, Plot of normalized amplitudes of the electrotonic coupling potential (open circles) and the chemical EPSP ( filled circles) as a function of time, with BAPTA and dopamine applied during the periods indicated. A second BAPTA injection $\sim 15$ min after dopamine confirmed the calcium-independent effects of the amine. $B 1, B 2$, Further evidence for the separation of intracellular pathways. Ineffectiveness of the tetanus in the presence of the chelator confirmed the successful injection of the latter, whereas dopamine still produced a potentiation. $C$, Bar plots from six experiments indicating changes in the mean ( \pm SEM) amplitude (\% control) of the coupling potential ( $e$; open bars) and the chemical EPSP $(c ;$ filled bars) that follow, in order, BAPTA, tetanus, and dopamine. The mean $(\mu)$ potentiations $( \pm$ SEM) evoked by dopamine after tetanization in this series $[\mu(e)$ $=24 \pm 15 \% ; \mu(c)=47 \pm 14 \%]$ did not differ statistically from control experiments $(p>0.05 ; n=6)$. Note that there is a small reduction in the chemical $\operatorname{EPSP}(\mu=12 \pm 6 \%)$ immediately after an injection of BAPTA. $D$, Plot from a control experiment in which a single tetanus was applied to NV III shortly after BAPTA injection.

hancements were persistent and did not differ significantly $(p>$ 0.1 ) from the DEP controls conducted in normal saline, as described above for the BAPTA experiments. We did not attempt to wash out APV/CPP because reversibility is difficult to demonstrate in this in vivo preparation, given the depth of the M-cell below the medullary surface $(1.5 \mathrm{~mm})$. These results indicate that the amine enhances the non-NMDA receptor-mediated component of the EPSP and that NMDA receptor activation is not required for these effects.

We also examined the effects of the non-NMDA receptor antagonist CNQX $(50 \mu \mathrm{M})$ on the induction and expression of the dopamine-evoked potentiation. Figure $6 C$ shows that the blocker had no effect on the electrotonic coupling potential, whereas it suppressed most, if not all, of the chemical EPSP such that the magnitude and waveform of the remaining response resembled that observed during continuous high-frequency stimulation (100 $\mathrm{Hz}$ ) of NVIII, used to fatigue chemical transmission (see Yang et al., 1990). When dopamine was applied in the presence of CNQX (Fig. 6D), the coupling potential was enhanced significantly, as expected, whereas the chemical component remained unchanged. The enhancement in the coupling potential after dopamine $($ mean $=34 \pm 8 \% ; n=3)$ did not differ from that in DEP controls $(p>0.1)$. Because the bulk of the chemically mediated EPSP at the resting potential was blocked by CNQX (see Wolszon et al., 1997), we could not assay directly for the effects of dopamine on the NMDAR-mediated component. However, the lack of effect of CNQX on the potentiation of the coupling potential demonstrates that the modulations of the electrotonic and chemical synaptic responses are attributable to independent expression mechanisms (see also Pereda et al., 1996).

\section{Voltage dependence of the chemical EPSC}

The NMDA receptor-mediated portion of the chemical EPSP is voltage-dependent (Wolszon et al., 1997), as shown in Figure 7. 

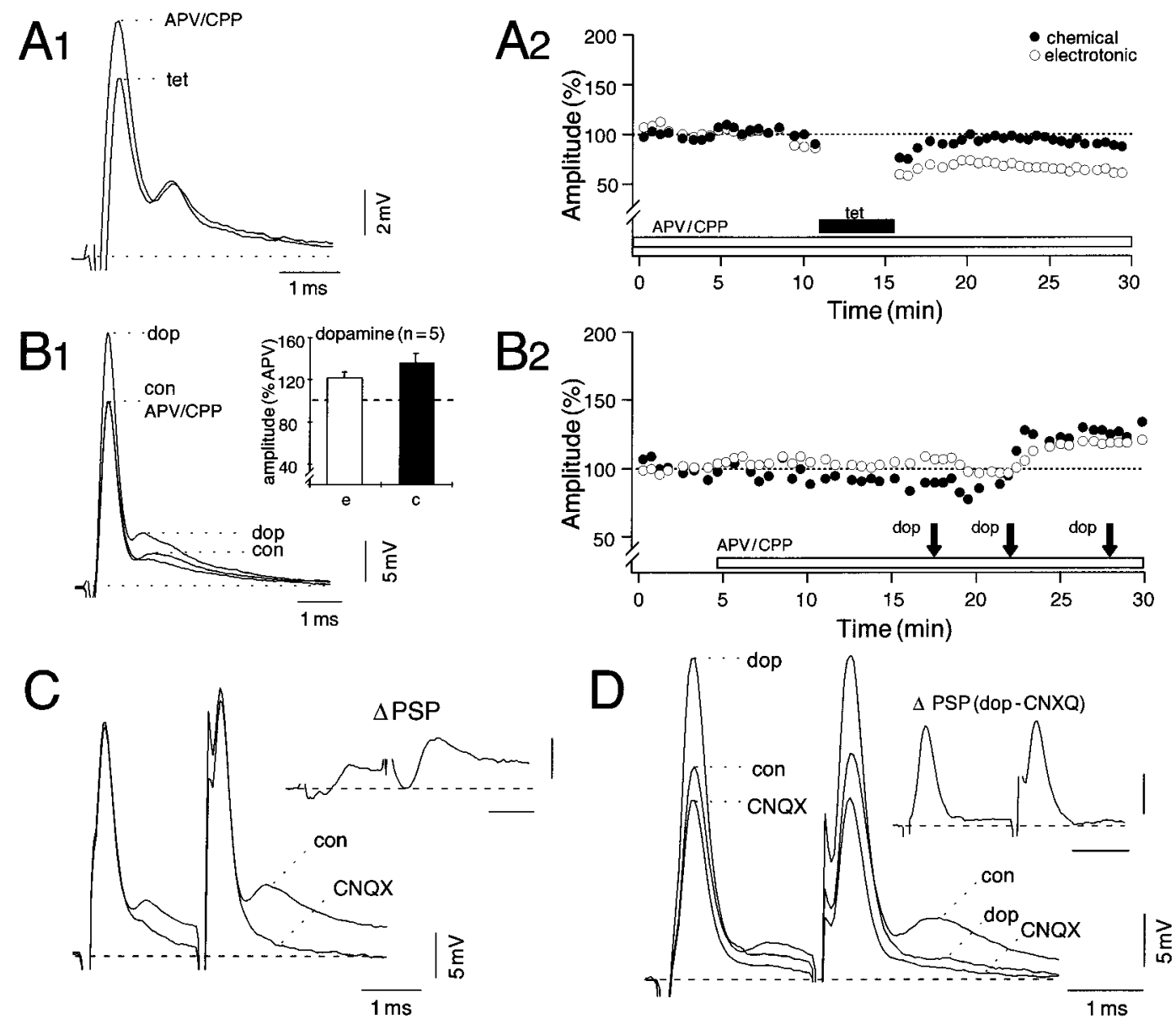

Figure 6. Dopamine-evoked potentiation of the AMPA receptor-mediated component. $A 1, A 2$, Averaged traces $(A 1)$ and the time course of changes in evoked NVIII responses $(A 2)$ before and after tetanization from a preparation continually superfused with saline containing APV and CPP (50 $\mu \mathrm{M}$ each) to block NMDA receptor activation. $B 1, B 2$, In the presence of the blockers, dopamine still produced a potentiation; the same format was used as in $A 1$ and $A 2$, respectively. The third dopamine application in $B 2$ confirms a saturating potentiation evoked by the amine. Inset, B1, Pooled data from five experiments showing modest potentiations of the mean response amplitudes of electrotonic coupling potential $(e)$ and the chemically mediated EPSP (c) after dopamine (100\% equals the average of corresponding values in APV/CPP). The mean $(\mu)$ dopamine-evoked potentiations $( \pm$ SEM) in the presence of APV/CPP $[\mu(e)=22 \pm 7 \% ; \mu(c)=36 \pm 8 \% ; n=5]$ did not differ significantly $(p>0.05)$ from control experiments $[\mu(e)=37 \pm 7 \%$; $\mu(c)=38 \pm 6 \% ; n=6]$. $C, D$, Effects of the non-NMDA receptor antagonist, CNQX, on NVIII-evoked responses in control $(C)$ and subsequently after the application of dopamine $(D)$. Synaptic facilitation produced by paired NVIII stimuli is used to illustrate the drug effects more clearly. $C$, Superimposed averages $(n=15)$ in control (con $)$ and 15 min after superfusion of the brain with saline containing $50 \mu \mathrm{M}$ CNQX. Note that the antagonist blocked most of the chemical EPSP, whereas the electrotonic coupling potential essentially was unaffected. $D$, In the presence of CNQX, dopamine substantially potentiates electrotonic coupling, but not the chemical EPSP. Insets, Digitally subtracted differences $(\triangle P S P)$ of the indicated responses showing the effect of CNQX on the chemical EPSP in control and showing dopamine-mediated enhancements of the coupling potential in the presence of CNQX. Calibrations are as for synaptic responses.

We used the discontinuous SEVC to ask if this voltage dependency could be used to distinguish the EPSC components that might be altered during LTP, despite the limitations to this method in a large neuron such as the M-cell. As shown in Figure $7 A$, the chemically mediated EPSC $(c)$ could be resolved clearly in SEVC with a time course comparable to that of the EPSP. This correspondence is expected, given the short M-cell time constant (Faber and Korn, 1978). In contrast, the current associated with the coupling potential $(e)$ could not be distinguished from the stimulus artifact and therefore appears truncated. When the EPSC was recorded at different holding potentials $(n=9)$, the typical current-voltage $(I-V)$ relationship (Fig. $7 B$ ) exhibited a marked increase in postsynaptic current at hyperpolarized potentials $(-92$ to $-112 \mathrm{mV})$, with a distinct point of inflection and a region of negative slope positive to $-70 \mathrm{mV}$. Only a small portion of the negative slope conductance region could be ex- plored because of the clamp limitations noted in Materials and Methods. The current at hyperpolarized levels is predominantly an AMPAR response, whereas the NMDAR-mediated component should be most evident during depolarization (Wolszon et al., 1997). This assumption was confirmed by comparing NVIIIevoked EPSCs recorded in control conditions and again after $\sim 30$ min superfusion of the brain with the AMPA receptor antagonist CNQX ( $1 \mathrm{~mm} ; n=2)$. During the interim, NVIIIevoked responses were recorded in current clamp. Figure $7 C$ shows the averaged responses at holding potentials of -63 and $-83 \mathrm{mV}$ in these two conditions. The EPSC amplitude at the hyperpolarized holding potential is larger than that at the depolarized level $(-63 \mathrm{mV})$ in the control, as expected, whereas in the presence of CNQX it is virtually undetectable at $-83 \mathrm{mV}$ and only partially reduced at $-63 \mathrm{mV}$. These results provide a protocol for isolating the AMPA/KA receptor-mediated compo- 


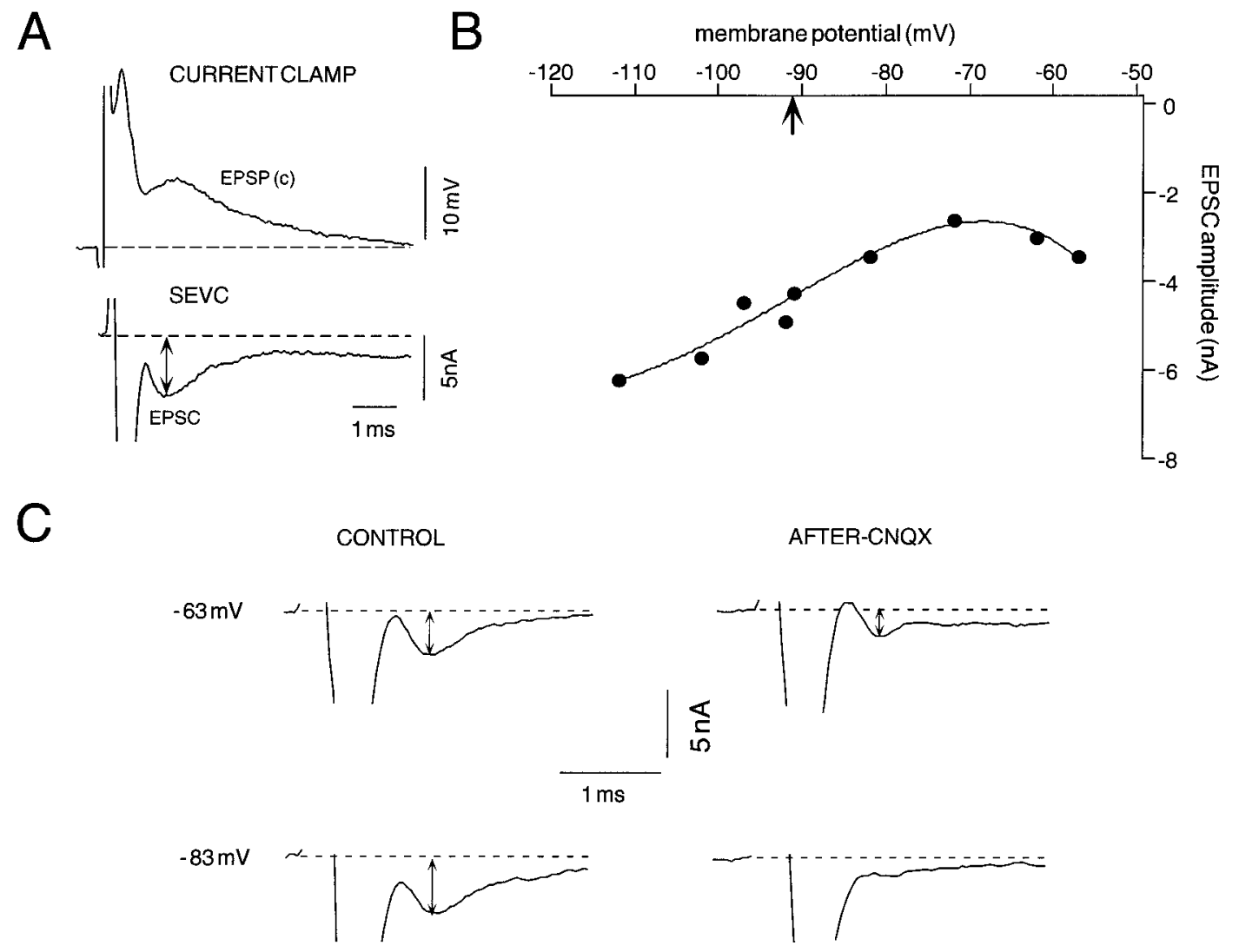

Figure 7. Single-electrode voltage clamp of the M-cell in the presence of CNQX allows for the decomposition of the chemically mediated response to NVIII stimulation into NMDA- and non-NMDAR-mediated components. Both current-clamp (bridge mode) and discontinuous single-electrode voltage-clamp (SEVC) records were obtained with the intracellular electrode. $A$, Sample intradendritic responses recorded in current clamp (top) and SEVC (bottom) at resting potential $\left(V_{\mathrm{r}}=-92 \mathrm{mV}\right.$; chopping frequency $\left.=10 \mathrm{kHz}\right)$ in control conditions. The currents associated with the coupling potential were truncated in SEVC (rise time $<200 \mu \mathrm{S}$ ), and only the chemically mediated EPSCs were measured (double-headed arrow) after leak correction (chopping frequency $=10 \mathrm{kHz}$ ). $B$, Current-voltage relationship of the synaptic response; the curve is a fit of the data with a fourth-order polynomial, with the arrow indicating the resting potential in this experiment. Note that the postsynaptic currents are enhanced noticeably at hyperpolarized potentials $(-112 \mathrm{mV})$, and the curve shows a distinct region of negative slope beyond $-70 \mathrm{mV}$. $C$, Traces represent averaged EPSCs $(n=$ 4) at two different holding potentials in control and after superfusion of the brain with $1 \mathrm{~mm}$ CNQX. Calibrations apply to all traces. Note that the magnitude of the control current is larger at the hyperpolarized potential $(-83 \mathrm{mV})$ than at the depolarized level $(-63 \mathrm{mV})$, whereas in the presence of CNQX the current at the former holding potential is reduced significantly; there is only a partial block at the depolarized level.

nents of the EPSC, by recording at resting potential and at hyperpolarized levels.

\section{Tetanus-induced LTP expressed by the AMPAR- mediated component of the chemical EPSP}

Figure 8 represents the approach used to determine whether the AMPA/KA receptor-mediated EPSC component was altered during LTP. At rest $\left(V_{\mathrm{r}}\right)$, the chemically mediated EPSC should reflect a substantially larger contribution from the AMPA receptors as compared with NMDAR, and that differential should be enhanced at more hyperpolarized potentials. At depolarized holding potentials the AMPAR component is diminished because of a reduction in the driving force, whereas NMDAR response should increase. However, these shifts might not be enough to allow for isolation of the latter with small depolarizations. We therefore calculated potentiation ratios (EPSC after tetanization/EPSC before tetanization) at different holding potentials. In the example of Figure $8 A 1$ the EPSC amplitudes after a tetanus are potentiated at resting potential $\left(V_{\mathrm{r}},-83 \mathrm{mV}\right)$ and during hyperpolarization $(-93 \mathrm{mV})$, but not during a $10 \mathrm{mV}$ depolarization $(-73 \mathrm{mV})$. The corresponding averaged $(n=15)$ EPSPs recorded in current clamp after the tetanus (Fig. 8A2) confirm potentiations of both electrotonic and chemical components of the control response to single and paired N V III stimuli. Paired stimuli were used in part because a single potentiated EPSP was at or above threshold for the orthodromic activation of the cell in this experiment. Figure $8 B$ represents the averaged potentiation ratios (pooled data from multiple experiments) versus changes in membrane potential $\left(\Delta V_{\mathrm{m}}\right)$ relative to the resting level $\left(V_{\mathrm{r}}\right)$. The fact that significant potentiations occurred at rest and at hyperpolarized holding potentials strongly supports the interpretation that tetanus-induced enhancements in the chemical component are in part attributable to changes in the AMPA/KA receptor-mediated component of the EPSP. We attach less significance to the lack of a notable effect at the depolarized levels, given the small sample size, although this result would suggest that the NMDAR component is either not potentiated or minimally modified.

\section{DISCUSSION}

\section{Implications of the interaction experiments}

The present results demonstrate that both homosynaptic LTP and the heterosynaptic DEP operate autonomously to alter the gain of 

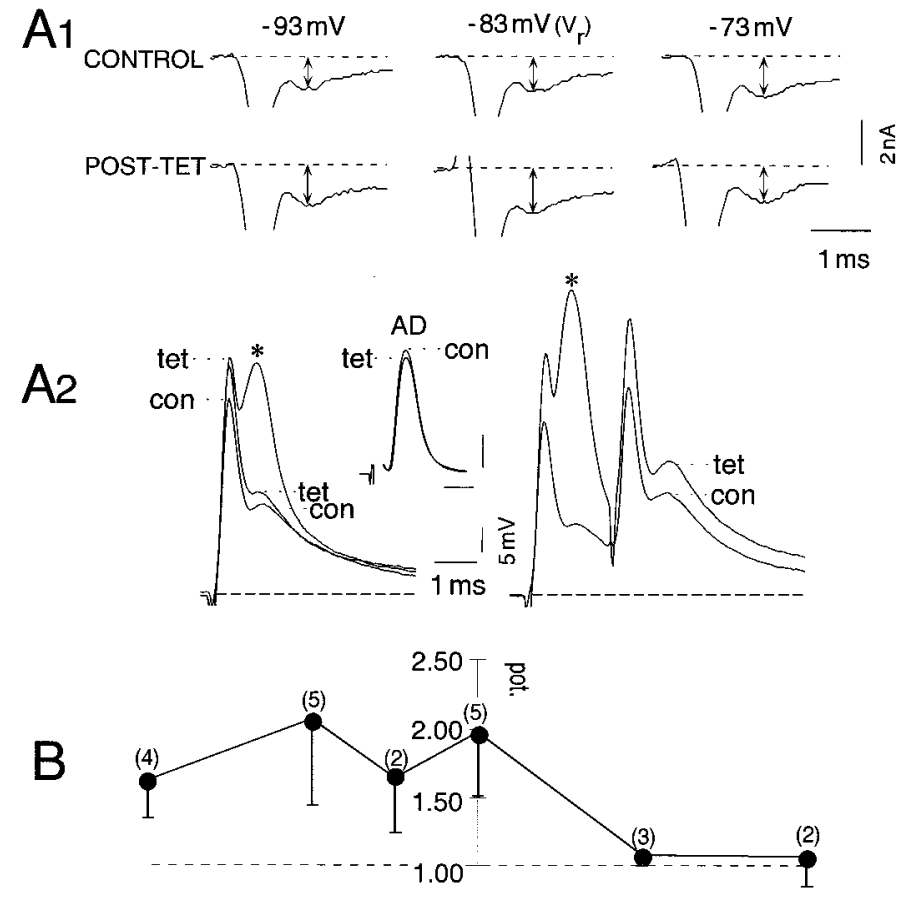

$0.50-$

$\begin{array}{ccccc}-20 & -10 & 0 & 10 & 20\end{array}$

Figure 8. Evidence that tetanus-induced LTP is expressed by the AMPA receptor-mediated EPSP component. At rest $\left(V_{\mathrm{r}}\right)$ the chemically mediated EPSP reflects contributions from both NMDA and AMPA receptors, with the latter dominating. At hyperpolarized holding potentials the AMPAR contribution increases and the NMDA component is diminished substantially, whereas with depolarization there is an increased NMDAR response caused by relief of the $\mathrm{Mg}^{2+}$ block. The response is dominated by AMPAR at hyperpolarized holding potentials, and the contribution of NMDAR increases progressively with depolarization. $A 1$, Properties of EPSCs recorded at different membrane potentials in control and after NVIII tetanization. Sample records are shown at the indicated holding potentials. Note that after tetanization the EPSC amplitudes are potentiated at resting potential $\left(V_{\mathrm{r}} ;-83 \mathrm{mV}\right)$ and during hyperpolarization $(-93 \mathrm{mV})$. The initial truncated response is the current caused by electrotonic coupling. A2, Corresponding EPSP changes recorded in current clamp, confirming the potentiation of both components of the M-cell control response (con) to NVIII stimulation (single and paired responses). Shown are superimposed averaged records indicating that the potentiated EPSP is above threshold for orthodromic activation of the cell (asterisk). Inset, Antidromically $(A D)$ evoked action potentials recorded at the same location. $B$, Graph of pooled data; ordinate, mean potentiation (pot.) of the EPSC amplitude (ratio of control and post-tetanus amplitudes), with error bars denoting SEM of the indicated number of experiments; abscissa, membrane potential $\left(\Delta V_{\mathrm{m}}\right)$ relative to resting level. Potentiations were significant at the resting potential and during hyperpolarizations, but not at depolarized holding potentials.

the eighth nerve synapses on the M-cell. The interaction experiments indicate that there must be a point of intracellular convergence common to both pathways. If a tetanus that produces a saturating LTP is applied first, dopamine is ineffective, and if the order of presentation is reversed, tetanization consistently produces an additional potentiation, with the aggregate level of enhancement equaling or exceeding that produced by the tetanus alone. The latter finding can be understood in part on the basis of the observation that, on average, LTP is greater than DEP. This differential was statistically significant for the chemical EPSP, but not for the electrotonic coupling potential, possibly because of variability in the magnitude of LTP. Because the two potentiations are not additive and LTP occludes the dopamine effect, we conclude that there is convergence of the underlying potentiating mechanisms at the level of individual synapses. In addition, previous application of dopamine increases the incidence of LTP induction from $70-75$ to $100 \%$. Interestingly, antagonism of the dopamine-activated pathways, with receptor blockers or the intracellular injection of PKI, produces the same increase in the incidence of LTP, regardless of whether dopamine itself is applied. These last two observations are consistent with the conclusion that dopamine has two modulatory actions, a priming effect and a potentiation, that can partially occlude LTP. Blocking the latter presumably also establishes a condition that favors LTP observation at the population level.

In rat striatum, high-frequency tetanization of corticostriatal fibers caused a persistent increase in dopamine release, suggesting a direct role for the amine in the induction of activitydependent plasticity (Ochi et al., 1995). This does not appear to be the case in the M-cell system, because the tetanizing paradigm still produced LTP in the presence of specific and broad-spectrum dopamine receptor antagonists. However, because the tetanus invariably induces LTP when it is preceded by dopamine, the latter also might prime the system. The modulatory effects of dopamine in hippocampus have been associated with the late, long-lasting, protein synthesis-dependent phase of LTP or L-LTP (Matthies and Reymann, 1993; Huang and Kandel, 1994, 1995; Nguyen et al., 1994). Although the potentiations studied in the M-cell system persisted for the duration of the recording session, the nature of the preparation generally precluded continuous intracellular recording for periods $>2 \mathrm{hr}$. Hence our observations do not address the modulatory effects of dopamine on the late phase. However, the relatively short onset of the dopamine effect suggests that the amines act locally, particularly in view of the distance $(250-300 \mu \mathrm{m})$ from the ejection site at the lateral dendrite to the soma. A recent study (Blitzer et al., 1995), in hippocampal area CA1, suggested that a cAMP-dependent pathway may gate early LTP (E-LTP), which does not depend on protein synthesis but does require PKA activity. Despite the uncertainty of whether dopamine effects are involved in L- or E-LTP or both, the PKA-mediated cAMP dependence of these phenomena (Frey et al., 1993; Matthies and Reymann, 1993; Huang and Kandel, 1994), coupled with evidence for dopaminergic innervation of this region (Cooper, 1991; Karen et al., 1992), suggests a role for the amine in modulating the efficacy of the hippocampal synapses. Similarly, in another study of the Schaffer-CA1 hippocampal synapses, dopamine D1/D5 receptor activation produced an $\sim 20-25 \%$ increase in the magnitude of synapse-specific early LTP (Otmakhova and Lisman, 1996). These effects may be related to the priming action of dopamine whereby it increases the likelihood that a tetanus produces LTP in the M-cell, although it did not increase the magnitude of LTP significantly in this system.

\section{Postsynaptic convergence of regulatory pathways}

We have shown that LTP induction does not depend on PKA activation and that, conversely, DEP does not depend on an increased intracellular $\mathrm{Ca}^{2+}$ concentration, thereby ruling out the possibility of convergence at the level of the second messengers. Indeed, Pereda et al. (1996) recently presented evidence suggesting that the activation of $\mathrm{Ca}^{2+} /$ calmodulin-dependent protein kinase II (CaMKII) induces LTP. Thus, our results are not consistent with a tetanus-induced activation of the cAMP 
PKA pathway triggered by coactivation of adenylyl cyclase by $\mathrm{Ca}^{2+}$ and native calmodulin (Rasmussen and Means, 1989), as proposed for the activity-dependent enhancement of presynaptic facilitation in Aplysia (Kandel et al., 1983; Abrams and Kandel, 1988; Elliot et al., 1989), or with the alternative that dopamine acts by elevating intracellular $\mathrm{Ca}^{2+}$ concentration (Civelli et al., 1993; Surmeier et al., 1995). They rather suggest that the two distinct kinase cascades converge on the same targets, namely the gap junctions and the non-NMDA AMPA/KA receptors or common intermediates. Also, LTP does not seem to involve a potentiation of the NMDAR-mediated component of the EPSP, although in the case of DEP that possibility was not tested directly. In addition, protein kinase C-mediated regulation of NMDA receptors, implicated in the modulation of the threshold for the induction of hippocampal LTP (Chen and Huang, 1992; Tingley et al., 1993), may be ruled out in the M-cell because PKC activation by phorbol esters has no effect on the NVIII-evoked synaptic responses (Silva et al., 1995).

Many of the mechanisms involved in neuronal plasticity depend on the phosphorylating effects of protein kinases (Malenka et al., 1989; Raymond et al., 1993a; Soderling, 1993 a,b; Schulman, 1995). Barring their role in the expression of genes in the nucleus (Kaang et al., 1993; Frank and Greenberg, 1994), most kinases implicated in alterations of synaptic efficacy act by regulating intracellular signal transduction pathways and/or by directly affecting neurotransmission. The latter may occur as a result of alterations in presynaptic transmitter release or postsynaptic modification of receptor channels via the conversion of receptors between nonfunctional and functional states or changes in singlechannel properties (Knapp and Dowling, 1987; Liman et al., 1989; Knapp et al., 1990; Greengard et al., 1991). The ionotropic glutamate receptors are good substrates for these types of kinasemediated modulations (Gassic and Hollmann, 1992; Roche et al., 1994; Nakazawa et al., 1995). There is substantial evidence for the modulation of the AMPA/kainate receptors by both CamKII (McGlade-McCulloh et al., 1993; Lisman, 1994; Tan et al., 1994) and PKA (Greengard et al., 1991; Raymond et al., 1993b; Wang et al., 1993; Blackstone et al., 1994). Similarly, gap junction connexins are also good substrates (Bennett and Verselis, 1992; Saez et al., 1993; Yeager and Nicholson, 1996) for the control of electrotonic coupling.

\section{A model for interactions between the regulatory pathways}

Figure $9 A$ summarizes the postulated intracellular regulatory pathways that, based on previous experimental findings (Wolszon and Faber, 1989; Yang et al., 1990; Pereda et al., 1992, 1994), lead to persistent enhancements in synaptic transmission in the M-cell system and follow the application of either dopamine or patterned presynaptic activity. Although the initial steps in the potentiations are independent, they clearly share a common intermediary or targets. Any model of our results needs also to address the findings that LTP (1) is greater in magnitude than DEP and (2) occludes the dopamine effect when activated first. Although these last two observations could be attributable to a subset of the synapses either not being accessible to dopamine or lacking downstream second messengers, we assume here that the population effects listed above pertain to single synapses. Our proposed model is described in terms of the chemical EPSP, although it may be extended to electrotonic coupling as well. It is based on evidence for consensus phosphorylation sites for the kinases involved on a variety of proteins. For example, glutamate recep-

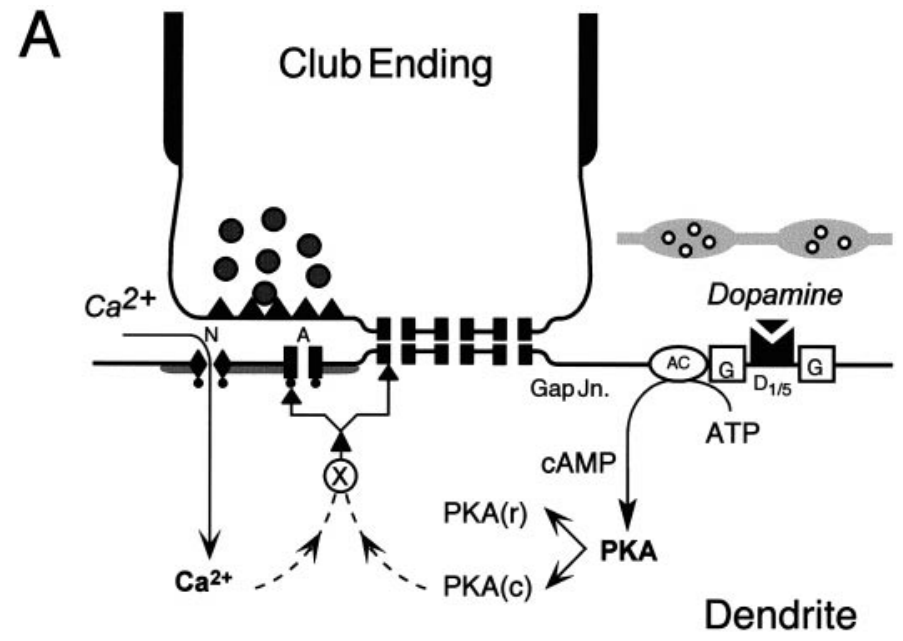

B

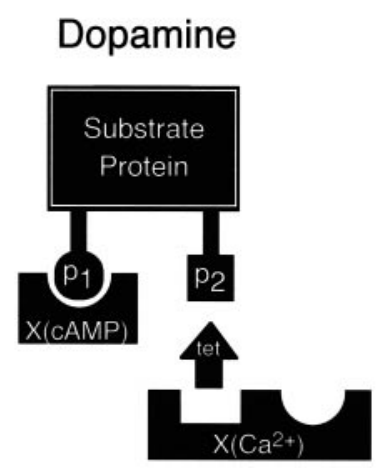

Tetanization

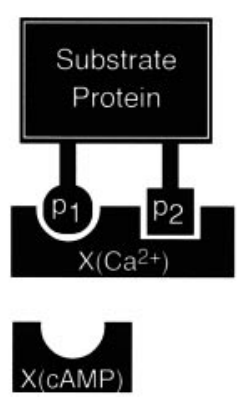

Figure 9. Scheme for the proposed interactions between the intracellular regulatory pathways leading to persistent enhancements in synaptic transmission in the M-cell. $A$, Postsynaptic regulatory pathways. Dopamine acts through the D1/5 receptor cascade, involving the activation of a G-protein $(G)$, adenyl cyclase $(A C)$, a postsynaptic increase in cAMP levels, and a consequent enhanced activation of the cAMP-dependent protein kinase $\mathrm{A}(P K A)$ via the dissociation of the complex of regulatory $[P K A(r)]$ and catalytic subunits $[P K A(c)]$. Chemical transmission at this locus involves both NMDA $(N)$ and non-NMDA/AMPA $(A)$ glutamate receptors, and the induction of LTP via tetanization requires intracellular elevations of $\mathrm{Ca}^{2+}$ via the NMDA receptor subtype. Potentiation is presumably downstream of PKA and calcium (dashed lines) and might involve an intermediary protein $(X)$. The interaction experiments suggest that these pathways converge either at $X$ or directly at the target protein, that is, the gap junctions (Gap Jn.) and glutamate receptors. B, Differential modulation of substrate proteins via phosphorylation could account for the observed interactions between intracellular pathways mediating tetanus- and dopamine-evoked potentiations. Shown is a model explaining the phosphorylation hypothesis. The substrate protein is depicted with phosphorylation sites $p_{1}$ and $p_{2}$, both of which could be potential targets for a $\mathrm{Ca}^{2+}$-activated kinase $X\left(\mathrm{Ca}^{2+}\right)$, but only one of them can be phosphorylated by the kinase activated by cAMP, $X(c A M P)$. When dopamine (Dop) is applied first, it could act via $X(c A M P)$ on one of the two sites, leaving room for further phosphorylation by $X\left(\mathrm{Ca}^{2+}\right)$ activated by the tetanus (Tet). The associated change in the magnitude of the synaptic response could be proportional to the number of sites phosphorylated such that dopamine first (Dop-Tet) causes a smaller change via $X(c A M P)$, because only one of the residues on the substrate protein is phosphorylated, whereas reversing the sequence of manipulations (TetDop) allows $X\left(\mathrm{Ca}^{2+}\right)$ to produce a maximal effect via both the available sites, leaving no further substrates for phosphorylation by $X(c A M P)$. 
tors are heteromeric combinations of various subunits (Barnes and Henley, 1992; Sommer and Seeburg, 1992), and there are conserved consensus sequences of amino acids within the subunits that contain multiple serine, threonine, or tyrosine phosphorylation residues (Keinanen et al., 1990; Egebjerg et al., 1991; Wang and Slater, 1994) for kinase-mediated activity. The multiplicity of these residues on neurotransmitter receptor proteins suggests that they may be regulated differentially by various protein kinases that recognize the same, or different, consensus sites on the receptor substrates.

Assume that a target protein (Fig. $9 B$ ) can be phosphorylated (p) by a calcium-dependent kinase, $X\left(\mathrm{Ca}^{2+}\right)$, at two sites ( $\mathrm{p}_{1}$ and $\left.\mathrm{p}_{2}\right)$, but at only one site $\left(\mathrm{p}_{1}\right)$ by a cAMP-dependent kinase, $X(\mathrm{cAMP})$. Activation of the $\mathrm{Ca}^{2+}$-dependent kinase first would leave no further sites available for the cAMP-dependent kinase, whereas in the reverse situation cAMP-dependent kinase can phosphorylate the $\mathrm{p}_{1}$ residue, leaving $\mathrm{p}_{2}$ open for additional phosphorylation by the $\mathrm{Ca}^{2+}$-dependent kinase. This simple scheme would explain the interactions we have observed if we assume that the magnitude of a given effect is proportional to the number of phosphorylated sites.

It has been suggested that CaMK-II, which phosphorylates the GluR1 subunit (Ser 627), also phosphorylates the equivalent residue on GluR6 because the GluR1 site is conserved in all AMPA/KA GluRs cloned so far (McGlade-McCulloh et al., 1993; Soderling, 1993 b). However, although PKA phosphorylates GluR6 (Ser 684; Raymond et al., 1993b; Wang et al., 1993), it does not phosphorylate the site on GluR1 (Yakel et al., 1995), presumably because of the lack of an ideal consensus sequence on the GluR1 protein (Hollmann et al., 1989). Thus the model would seem to be consistent with data on AMPA/kainate receptors, shown here to express both potentiations. In the case of the M-cell the involvement of an intermediary protein common to both potentiating pathways cannot be ruled out, particularly because a preliminary immunohistochemical assay for glutamate receptor subunits on the lateral dendrite has revealed that NMDAR1 is colocalized with GluR2/3, but not with GluR1, which, although present, seems to be distributed more diffusely (Sur et al., 1994). Additionally, there have been no assays for GluR6 or other receptor subtypes thus far.

Although the most parsimonious explanation for the lack of an effect of dopamine after LTP induction is the intracellular convergence of the two modulatory pathways, an alternative would be that there is a second effect of the amine, namely the depression of recently enhanced connections. This effect would have to cancel the normal DEP, and we consider it unlikely that the two opposing actions would be so well balanced in the majority of the experiments.

\section{DEP and LTP of electrotonic coupling}

Enhancements in the gain of NVIII-M-cell synapses often affect both gap junctional coupling and chemical transmission together. This observation also might favor the alternative of an intermediate target, although the responses do not always change in parallel. The fact that it is difficult to decouple the two components experimentally, except under conditions of spontaneous decoupling (Pereda and Faber, 1996) or by pharmacological manipulations, implies that one set of factors also might influence the electrotonic coupling potential. The phosphorylating effects of kinases on gap junctional proteins (Bennett and Verselis, 1992) have not been investigated as extensively as their chemical counterparts, although connexin-43, whose presence in the dendrite has been suggested (Yox et al., 1990), is phosphorylated by protein kinases (Lau et al., 1996; Yeager and Nicholson, 1996), including PKA, in other systems (Rorig et al., 1995). Similarly, connexin-32, another candidate for these junctions, also is phosphorylated by PKA, protein kinase C, and CaMKII (Saez et al., 1986, 1993; Moreno et al., 1993). Although PKA and PKC share a common serine residue, CaMKII acts via a site different from those used by the other kinases (Saez et al., 1990). Thus, it remains to be determined whether the model proposed here pertains to an intermediary common to the regulation of both modes of transmission.

\section{Behavioral significance of the observed phenomenon}

The ubiquitous nature of dopamine and its varied modulatory effects in the neostriatum (Surmeier et al., 1995), the prefrontal cortex (Williams and Goldman-Rakic, 1995), and other regions of the brain have been well documented. Our results and those of others demonstrate its potential to modulate synaptic strength directly and to regulate activity-dependent plasticities. The interactions between these two mechanisms may have significant nonlinear effects on the properties of the neural networks. Furthermore, the M-cell commands a vital escape reflex initiated by auditory stimuli (Eaton et al., 1977; Zottoli, 1979). It has been assumed that LTP of the auditory pathway would lower the behavioral threshold for this reflex (Korn and Faber, 1996), and it would sensitize the fish also, producing a heightened state of arousal. The latter is comparable to the suggestion that LTP in hippocampus may not be a learning mechanism per se but rather a neural equivalent to an arousal or attention mechanism that may nonspecifically increase the effectiveness of discrete external stimuli (Shors and Matzel, 1997). It has been suggested that modification of the synapses on the M-cell may be involved in the adaptive tuning of reflexive behaviors because there also is LTP of feed-forward inhibition from the contralateral auditory nerve (Charpier et al., 1995; Oda et al., 1995). Such behavioral modifications also might be effected heterosynaptically by means of an endogenous dopaminergic system, which could distribute a signal representing information about future expectations (Montague et al., 1996). In this context it would be worthwhile to identify the dopaminergic pathway itself and the determinants of its activity patterns.

\section{REFERENCES}

Abrams TW, Kandel ER (1988) Is contiguity detection in classical conditioning a system or a cellular property? Learning in Aplysia suggests a possible molecular site. Trends Neurosci 11:128-135.

Barnes JM, Henley JM (1992) Molecular characteristics of excitatory amino acid receptors. Prog Neurobiol 39:113-133.

Bennett MV, Verselis VK (1992) Biophysics of gap junctions. Semin Cell Biol 3:29-47.

Blackstone C, Murphy TH, Moss SJ, Baraban JM, Huganir RL (1994) Cyclic AMP and synaptic activity-dependent phosphorylation of AMPA-preferring glutamate receptors. J Neurosci 14:7585-7593.

Bliss TVP, Collingridge GL (1993) A synaptic model of memory: longterm potentiation in the hippocampus. Nature 361:31-39.

Bliss TVP, Lomo T (1973) Long-lasting potentiation of synaptic transmission in the dentate area of the anaesthetized rabbit following stimulation of the perforant path. J Physiol (Lond) 232:331-356.

Blitzer RD, Wong T, Nouranifar R, Iyengar R, Landau E (1995) Postsynaptic cAMP pathway gates early LTP in hippocampal CA1 region. Neuron 15:1403-1414.

Charpier S, Behrends JC, Triller A, Faber DS, Korn H (1995) Latent inhibitory connections become functional during activity-dependent plasticity. Proc Natl Acad Sci USA 92:117-120.

Chen L, Huang L-YM (1992) Protein kinase C reduces magnesium block of NMDA receptor channels as a mechanism of modulation. Nature 356:521-523. 
Civelli O, Bunzow JR, Grandy DK (1993) Molecular diversity of the dopamine receptors. Annu Rev Pharmacol Toxicol 32:281-307.

Cooper SJ (1991) Interactions between endogenous opioids and dopamine: implications for reward and aversion. In: The mesolimbic dopamine system: from motivation to action (Wilner P, Scheel-Kruger J, eds), pp 331-366. New York: Wiley.

Eaton RC, Bombardieri RA, Meyer DL (1977) The Mauthner-initiated startle response in teleost fish. J Exp Biol 66:65-81.

Egebjerg J, Bettler B, Hermans-Borgmeyer I, Heinemann S (1991) Cloning of a cDNA for a glutamate receptor subunit activated by kainate but not AMPA. Nature 351:745-748.

Elliot LS, Dudai Y, Kandel ER, Abrams TW (1989) Calcium/calmodulin sensitivity may be common to all forms of neural adenylate cyclase. Proc Natl Acad Sci USA 86:9564-9568.

Faber DS, Korn H (1978) Electrophysiology of the Mauthner cell: basic properties, synaptic mechanisms, and associated networks. In: Neurobiology of the Mauthner cell (Faber DS, Korn H, eds), pp 47-132. New York: Raven.

Faber DS, Korn H, Lin J-W (1991) Role of medullary networks and postsynaptic membrane properties in regulating Mauthner cell responsiveness to sensory excitation. Brain Behav Evol 37:286-297.

Fay RR, Olsho LW (1979) Discharge patterns of lagenar and saccilar neurons of goldfish eighth nerve: displacement sensitivity and directional characteristics. Comp Biochem Physiol [A] 62:377-386.

Frank DA, Greenberg ME (1994) CREB: a mediator of long-term memory from mollusks to mammals. Cell 79:5-8.

Frey U, Huang Y-Y, Kandel ER (1993) Effects of cAMP simulate a late phase of LTP in hippocampal CA1 neurons. Science 260:1661-1664.

Furshpan EJ (1964) Electrical transmission at an excitatory synapse in a vertebrate brain. Science 144:878-880.

Furshpan EJ, Furukawa T (1962) Intracellular and extracellular responses of the several regions of the Mauthner cell of the goldfish. J Neurophysiol 25:732-771.

Gassic GP, Hollmann M (1992) Molecular biology of glutamate receptors. Annu Rev Physiol 54:507-536.

Greengard P, Jen J, Nairn AC, Stevens CF (1991) Enhancement of glutamate response by cAMP-dependent protein kinase in hippocampal neurons. Science 253:1135-1138.

Gribkoff VK, Ashe JH (1984) Modulation by dopamine of population responses and cell membrane properties of hippocampal CA1 neurons in vitro. Brain Res 292:327-338.

Hollmann M, O'Shea-Greenfield A, Rogers SW, Heinemann S (1989) Cloning by functional expression of a member of the glutamate receptor family. Nature 342:643-648.

Huang Y-Y, Kandel ER (1994) Recruitment of long-lasting and protein kinase A-dependent long-term potentiation in the CA1 region of hippocampus requires repeated tetanization. Learning Memory 1:74-82.

Huang Y-Y, Kandel ER (1995) D1/D5 receptor agonists induce a protein synthesis-dependent late potentiation in the CA1 region of the hippocampus. Proc Natl Acad Sci USA 92:2446-2450.

Jay TM, Burette F, Laroche S (1996) Dopaminergic modulation of longterm potentiation in the hippocampal-prefrontal cortex pathway. Soc Neurosci Abstr 22:332.

Kaang BK, Kandel ER, Grant SG (1993) Activation of cAMPresponsive genes by stimuli that produce long-term facilitation in Aplysia sensory neurons. Neuron 10:427-435.

Kandel ER, Abrams T, Bernier L, Carew TJ, Hawkins RD, Schwartz JH (1983) Classical conditioning and sensitization show aspects of the same molecular cascade in Aplysia. Cold Spring Harb Symp Quant Biol 48:821-830.

Karen DP, Doze VA, Madison DV, Browning MD (1992) Isoproterenol increases the phosphorylation of the synapsins and increases synaptic transmission in dentate gyrus, but not in area CA1, of the hippocampus. Hippocampus 2:59-64.

Keinanen K, Wisden W, Sommer B, Werner P, Herb A, Verdoorn TA, Sakmann B, Seeburg PH (1990) A family of AMPA-selective glutamate receptors. Science 249:556-560.

Knapp AG, Dowling JE (1987) Dopamine enhances excitatory aminoacid gated conductances in cultured retinal horizontal cells. Nature 325:437-439.

Knapp AG, Schmidt KF, Dowling JE (1990) Dopamine modulates the kinetics of ion channels gated by excitatory amino acids in retinal horizontal cells. Proc Natl Acad Sci USA 87:767-771.

Korn H, Faber DS (1996) Escape behavior-brainstem and spinal cord circuitry and function. Curr Opin Neurobiol 6:826-832.
Korn H, Faber DS, Triller A (1990) Convergence of morphological, physiological, and immunocytochemical techniques for the study of single Mauthner cells. In: Handbook of chemical neuroanatomy, Vol 8 (Bjorklund A, Hokfelt T, Wouterlood T, van den Pol AN, eds), pp 403-480. Amsterdam: Elsevier.

Kuffler SW, Nicholls JG, Martin RA (1984) Transformation of information by synaptic action in individual neuron. In: From neuron to brain (Kuffler SW, Nicholls JG, Martin AR, eds), pp 413-420. Sunderland, MA: Sinauer.

Lau AF, Kurata WE, Kanemitsu MY, Loo LW, Warn-Cramer BJ, Eckhart W, Lampe PD (1996) Regulation of connexin-43 function by activated tyrosine protein kinases. J Bioenerg Biomembr 28:358-368.

Liman ER, Knapp AG, Dowling JE (1989) Enhancement of kainategated currents in retinal horizontal cells by cAMP-dependent protein kinase. Brain Res 481:399-402.

Lin JW, Faber DS (1988) Synaptic transmission mediated by single club endings on the goldfish Mauthner cell. II. Plasticity of excitatory postsynaptic potentials. J Neurosci 8:1313-1325.

Lisman J (1994) The CaM kinase II hypothesis for the storage of synaptic memory. Trends Neurosci 17:406-412.

Malenka RC, Kauer JA, Perkel DJ, Mauk MD, Kelly PT, Nicoll RA, Waxham MN (1989) An essential role for postsynaptic calmodulin and protein kinase activity in long-term potentiation. Nature 340:554-557.

Matthies H, Reymann KG (1993) Protein kinase A inhibitors prevent the maintenance of hippocampal long-term potentiation. NeuroReport 4:712-714.

McGlade-McCulloh E, Yamamoto H, Tan SE, Brickey DA, Soderling TR (1993) Phosphorylation and regulation of glutamate receptors by calcium/calmodulin-dependent protein kinase II. Nature 362:640-642.

McNaughton BL (1982) Long-term enhancement and short-term potentiation in rat fascia dentata act through different mechanisms. J Physiol (Lond) 324:249-262.

Montague PR, Dayan P, Sejnowski TJ (1996) A framework for mesencephalic dopamine system based on predictive Hebbian learning. J Neurosci 16:1936-1947.

Moreno AP, Fishman GI, Eghbali B, Spray DC (1993) Unmasking electrophysiological properties of connexins 32 and 43: transfection of communication deficient cells with wild type and mutant connexins. In: Progress in cell research, Vol 3 (Hall JE, Zampighi GA, Davis RM, eds), pp 127-132. Amsterdam: Elsevier.

Nakazawa K, Mikawa S, Hashikawa T, Ito M (1995) Transient and persistent phosphorylation of AMPA-type glutamate receptor subunits in cerebellar Purkinje cells. Neuron 15:697-709.

Nguyen PV, Abel T, Kandel ER (1994) Requirement of a critical period of transcription for induction of a late phase of LTP. Science 265:1104-1107

Ochi M, Inoue H, Koizumi S, Shibata S, Watanabe S (1995) Long-term enhancement of dopamine release by high frequency tetanic stimulation via a $N$-methyl-D-aspartate-receptor-mediated pathway in rat striatum. Neuroscience 66:29-36.

Oda Y, Charpier S, Murayama Y, Suma C, Korn H (1995) Long-term potentiation of glycinergic inhibitory synaptic transmission. J Neurophysiol 74:1056-1074.

Otmakhova NA, Lisman JE (1996) D1/D5 dopamine receptor activation increases the magnitude of early long-term potentiation at CA1 hippocampal synapses. J Neurosci 16:7478-7486.

Pereda A, Faber DS (1996) Activity-dependent short-term enhancement of intracellular coupling. J Neurosci 16:983-992.

Pereda A, Triller A, Korn H, Faber DS (1992) Dopamine enhances both electrotonic coupling and chemical excitatory postsynaptic potentials at mixed synapses. Proc Natl Acad Sci USA 89:12088-12092.

Pereda AE, Nairn AC, Wolszon LR, Faber DS (1994) Postsynaptic modulation of synaptic efficacy at mixed synapses on the Mauthner cell J Neurosci 14:3704-3712.

Pereda A, Bell T, Czernik AJ, Faber DS (1996) Calcium-dependent enhancement of gap junctional conductance. Soc Neurosci Abstr 22:1511.

Pereda A, Bell T, Chang B, Czernik A, Nairn A, Soderling T, Faber DS (1998) CaM-KII mediates synaptically-induced enhancement of gap junctional conductance and glutamatergic transmission. Proc Natl Acad Sci USA 95:13272-13277.

Pereda A, Smith M, Faber DS (1998) Heterogeneity of gap junctional communication between individual afferents and a common target neuron. Soc Neurosci Abstr 24:1573. 
Rasmussen CD, Means AR (1989) Calmodulin, cell growth, and gene expression. Trends Neurosci 12:433-438.

Raymond AL, Blackstone CD, Huganir RL (1993a) Phosphorylation of amino acid neurotransmitter receptors in synaptic plasticity. Trends Neurosci 16:147-153.

Raymond AL, Blackstone CD, Huganir RL (1993b) Phosphorylation and modulation of recombinant GluR6 glutamate receptors by cAMPdependent protein kinase. Nature 361:637-641.

Roche KW, Tingley WG, Huganir RL (1994) Glutamate receptor phosphorylation and synaptic plasticity. Curr Opin Neurobiol 4:383-388.

Rorig B, Klausa G, Sutor B (1995) Dye coupling between pyramidal neurons in developing rat prefrontal and frontal cortex is reduced by protein kinase A activation and dopamine. J Neurosci 15:7386-7400.

Saez JC, Spray DC, Nairn AC, Hertzberg EL, Greengard P, Bennett MLV (1986) cAMP increases junctional conductance and stimulates phosphorylation of the $27 \mathrm{kDa}$ principal gap junctional polypeptide. Proc Natl Acad Sci USA 83:2473-2477.

Saez JC, Nairn AC, Czernik AJ, Spray DC, Hertzberg EL, Greengard P, Bennett MLV (1990) Phosphorylation of connexin-2, a hepatocyte gap-junction protein, by cAMP-dependent protein kinase, protein kinase $\mathrm{C}$, and $\mathrm{Ca}^{2+} /$ calmodulin-dependent protein kinase II. Eur J Biochem 192:263-273.

Saez JC, Berthoud VM, Moreno AP, Spray DC (1993) Gap junctions. Multiplicity of controls in differentiated and undifferentiated cells and possible functional implications. In: Advances in second messenger and phosphoprotein research, Vol 27 (Shenolikar SS, Nairn AC, eds), pp 163-198. New York: Raven.

Sarvey JM, Burgard EC, Decker G (1989) Long-term potentiation: studies in the hippocampal slice. J Neurosci Methods 28:109-124.

Schulman H (1995) Protein phosphorylation in neuronal plasticity and gene expression. Curr Opin Neurobiol 5:375-381.

Shors TJ, Matzel LD (1997) Long-term potentiation: what's learning got to do with it? Behav Brain Sci 20:597-655.

Silva A, Kumar S, Pereda A, Faber DS (1995) Regulation of synaptic strength at mixed synapses: effects of dopamine receptor blockade and protein kinase C activation. Neuropharmacology 34:1559-1565.

Soderling TR (1993a) Calcium/calmodulin-dependent protein kinase II: role in learning and memory. Soc Neurosci Abstr 19:1256.

Soderling TR (1993b) Neuronal functions of calmodulin-dependent protein kinase II. Mol Cell Biochem 127:93-101.

Sommer B, Seeburg PH (1992) Glutamate receptor channels: novel properties and new clones. Trends Pharmacol 13:291-296.

Staubli U, Otaky N (1994) Serotonin controls the magnitude of LTP induced by theta bursts via an action on NMDA-receptor-mediated responses. Brain Res 643:10-16.

Sur C, Wenthold R, Triller A (1994) Differential cellular distribution of excitatory amino acid receptors on the M-cell of the teleost. Soc Neurosci Abstr 20:489.

Surmeier DJ, Bargas J, Hemmings Jr HC, Nairn AC, Greengard P (1995) Modulation of calcium currents by a D1 dopaminergic protein kinase/ phosphatase cascade in rat neostriatal neurons. Neuron 14:385-397.

Tan S-E, Wenthold RJ, Soderling TR (1994) Phosphorylation of AMPA-type glutamate receptors by calcium/calmodulin-dependent protein kinase II and protein kinase $\mathrm{C}$ in cultured hippocampal neurons. J Neurosci 14:1123-1129.

Tingley WG, Roche KW, Thompson AK, Huganir RL (1993) Regulation of NMDA receptor phosphorylation by alternative splicing of the C-terminal domain. Nature 364:70-73.

Villani F, Johnston D (1993) Serotonin inhibits induction of long-term potentiation at commissural synapses in the hippocampus. Brain Res 606:304-308.

Wang LY, Taverna F, Huang XP, MacDonald JF, Hampson DR (1993) Phosphorylation and modulation of kainate receptor (GluR6) by cAMP-dependent protein kinase. Science 259:1173-1175.

Wang YT, Slater MW (1994) Regulation of NMDA receptors by tyrosine kinases and phosphatases. Nature 369:233-235.

Williams GV, Goldman-Rakic PS (1995) Modulation of memory fields by dopamine D1 receptors in prefrontal cortex. Nature 376:572-575.

Wolszon L, Faber DS (1988) Fast EPSPs evoked in the Mauthner cell by sensory afferents are due to NMDA receptor activation. Soc Neurosci Abstr 14:939.

Wolszon LR, Faber DS (1989) The effects of postsynaptic levels of cyclic AMP on excitatory and inhibitory responses of an identified central neuron. J Neurosci 9:784-797.

Wolszon LR, Pereda AE, Faber DS (1997) A fast synaptic potential mediated by NMDA and non-NMDA receptors. J Neurophysiol 78:2693-2706.

Yakel JL, Vissavajjhala P, Derkach VA, Brickey DA, Soderling TR (1995) Identification of a calcium/calmodulin-dependent protein kinase II regulatory phosphorylation site in non- $N$-methyl-D-aspartate glutamate receptors. Proc Natl Acad Sci USA 92:1376-1380.

Yang X-D, Korn H, Faber DS (1990) Long-term potentiation of electrotonic coupling at mixed synapses. Nature 348:542-545.

Yeager M, Nicholson BJ (1996) Structure of gap junction intracellular channels. Curr Opin Struct Biol 6:183-192.

Yox DP, Faber DS, Nicholson BJ (1990) Gap junction antibody attenuates electrical coupling between the goldfish Mauthner (M-) cell and its eighth nerve afferents. Soc Neurosci Abstr 16:185.

Zalutsky RA, Nicoll RA (1991) Comparison of two forms of long-term potentiation in single hippocampal neurons. Science 251:856.

Zottoli SJ (1979) Correlation of the startle reflex and Mauthner cell auditory responses in unrestrained goldfish. J Exp Biol 66:243-254. 